NBER WORKING PAPER SERIES

\title{
THE IMPACT OF COVID-19 ON OLDER WORKERS' EMPLOYMENT AND SOCIAL SECURITY SPILLOVERS
}

\author{
Gopi Shah Goda \\ Emilie Jackson \\ Lauren Hersch Nicholas \\ Sarah See Stith \\ Working Paper 29083 \\ http://www.nber.org/papers/w29083 \\ NATIONAL BUREAU OF ECONOMIC RESEARCH \\ 1050 Massachusetts Avenue \\ Cambridge, MA 02138 \\ July 2021
}

We would like to thank Rolando Hernandez Gomez and Sasmira Matta for outstanding research assistance. The research reported herein was performed pursuant to grant RDR18000003 from the US Social Security Administration (SSA), funded as part of the Retirement and Disability Research Consortium. The opinions and conclusions expressed are solely those of the authors and do not represent the opinions or policy of SSA, any agency of the Federal Government, or NBER. Neither the United States Government nor any agency thereof, nor any of their employees, makes any warranty, express or implied, or assumes any legal liability or responsibility for the accuracy, completeness, or usefulness of the contents of this report. Reference herein to any specific commercial product, process or service by trade name, trademark, manufacturer, or otherwise does not necessarily constitute or imply endorsement, recommendation or favoring by the United States Government or any agency thereof. Jackson gratefully acknowledges support from the Peter G. Peterson Foundation for a post-doctoral fellowship at NBER during which part of this research was conducted.

NBER working papers are circulated for discussion and comment purposes. They have not been peer-reviewed or been subject to the review by the NBER Board of Directors that accompanies official NBER publications.

(C) 2021 by Gopi Shah Goda, Emilie Jackson, Lauren Hersch Nicholas, and Sarah See Stith. All rights reserved. Short sections of text, not to exceed two paragraphs, may be quoted without explicit permission provided that full credit, including $\odot$ notice, is given to the source. 
The Impact of Covid-19 on Older Workers' Employment and Social Security Spillovers

Gopi Shah Goda, Emilie Jackson, Lauren Hersch Nicholas, and Sarah See Stith

NBER Working Paper No. 29083

July 2021

JEL No. H53,H55,J22,J23,J26

\begin{abstract}
$\underline{\text { ABSTRACT }}$
The COVID-19 pandemic and associated mitigation strategies exacted a large economic toll on large portions of the United States population. For older and disabled workers, the effects could be more persistent and fiscally costly than the impacts experienced by young, healthy workers due to the spillovers onto Social Security. We use Current Population Survey, Social Security administrative data on applications for retirement and disability benefits, and Google Trends data to assess the impact of COVID-19 on older adults age 50-70. We find that employment for this group dropped substantially more than would have been predicted prior to the pandemic: employment for 50-61 year olds was 5.7 pp (8.3 percent) lower, while employment for 62-70year- olds was 3.9 pp (10.7 percent) lower. For people aged 50-61, unemployment and labor force exits due to reasons other than disability and retirement represented 63 and 30 percent of the employment decline, respectively. For those aged 62-70, the two largest components of the reduction were unemployment (50 percent) and retirement-driven labor force exits (30 percent). We find evidence of declines in reporting a labor force exit due to disability (4-5 percent), applications for disability insurance (15 percent), and Google search intensity for disability ( 7 percent). Retirement benefit claiming remains largely unchanged overall, though we find evidence that applicants substituted towards filing for benefits via the internet. We explore potential mechanisms and find evidence for both supply- and demand-side explanations.

Gopi Shah Goda

Stanford University

SIEPR

366 Galvez St.

Stanford, CA 94305

and NBER

gopi@stanford.edu

Emilie Jackson

NBER

1050 Massachusetts Ave

Cambridge, MA 02138

jacksone@nber.org

Lauren Hersch Nicholas

Colorado School of Public Health

Aurora, CO

lauren.h.nicholas@cuanschutz.edu

Sarah See Stith

University of New Mexico

Department of Economics

1915 Roma Ave NE, \#1006B

Albuquerque, NM 87131

ssstith@unm.edu
\end{abstract}




\section{Introduction}

The COVID-19 global pandemic created an unprecedented time of economic and social disruption, and transformed the economy from one of the strongest labor markets to recordbreaking numbers of job losses almost overnight. The U.S. went from a few dozen confirmed cases of COVID-19, caused from a novel coronavirus, to almost 800,000 cases in less than two months from late February to late April 2020, and has more than 30 million confirmed cases as of this writing. In an effort to slow the spread of COVID-19, several states and localities issued guidelines regarding social distancing and orders requiring workers to stay at home, preventing many from showing up to work and devastating businesses around the country. Even when states failed to offer such guidance, mobility data indicated a marked reduction in travel outside the house as Americans tried to avoid the threat of disease.

The COVID-19 pandemic represents a particular threat to older and disabled workers, who are economically and physically vulnerable to the twin threats of long-term health impacts from virus spread and shutdown policies that reduced labor demand and supply. COVID-19 is associated with higher rates of mortality among those at older ages and with comorbidities (Rosenthal et al., 2020). While the longer-term health effects of COVID-19 are still not well understood, preliminary evidence suggests that lingering symptoms may preclude a return to work for those with long-COVID or other persistent health concerns. Older and disabled workers are also more vulnerable to permanent labor market exits during recession-induced job losses, and have additional margins of response due to the potential availability of benefits through Social Security.

In this paper, we examine labor market outcomes and Social Security spillovers among individuals aged 50-70, who comprise approximately 40 percent of the labor force, over the course of the economic recession caused by the COVID-19 pandemic. We use the Current Population Survey (CPS) to track monthly employment outcomes. Our analyses distinguish between workers age 50-61 and 62-70, due to differences in eligibility for early retirement benefits and different rates of baseline employment across these two groups. We also examine 
overall monthly claims for Social Security disability insurance (SSDI), Supplemental Security Income (SSI), and Social Security retirement benefits as well as Google Trends data on online searches for retirement and disability to analyze benefit claiming behavior and search activity that may indicate future benefit claiming plans.

We find evidence that employment among older workers declined sharply in April, before slowly recovering and leveling off, leading to an average deviation from predicted employment of 5.7 percentage points (for 50-61-year-olds; $8.3 \%$ ) and 3.9 percentage points (for 62-70year-olds; 10.7\%) between March 2020 and March 2021. For 50-61-year-olds, approximately 63 percent of the decline is due to increases in unemployment, and 30 percent is due to increases in labor force exits due to reasons other than retirement and disability. Among 62-70-year-olds, the decline attributed to increases in unemployment is 50 percent and the next largest component is an increase in retirement of 1.2 percent, accounting for 30 percent of the employment decline, and representing a 2.4 percent increase relative to the baseline.

Our results show consistent evidence of declines in labor market exits due to disability and applications for disability after the start of the pandemic. Older workers are 0.4 percentage points (4-5 percent) less likely to report exiting the labor force due to disability in the first year after the start of the pandemic. We find a larger (15 percent) decrease in overall disability applications, which appears to be driven by reductions in applications for SSI and concurrent SSI and SSDI applications, and a decline in Google search intensity for disability and related words of 5 percent.

The implications of the pandemic for retirement behavior are more mixed. While the CPS shows increases in labor market exits due to retirement for 62-70-year-olds in particular, we do not find evidence that retirement applications changed differentially between March 2020 and March 2021 relative to predicted levels. However, our results do show a shift from SSA retirement applications filed offline to those filed via the internet. Our analysis of online search activity for retirement-related search terms finds declines of 7 percent relative to the period prior to the pandemic. Together, our results suggest that elevated labor market 
exits due to retirement have not yet been accompanied by a large increase in older workers transitioning to Social Security during the first 12 months after the pandemic relative to what would have been predicted in its absence.

We also examine heterogeneity in the labor market outcomes by demographic characteristics. A differential impact on the more vulnerable is persistent throughout our results, in line with the marked reduction in SSI applications. Those with less education, Blacks, and Hispanics generally experienced worse labor market outcomes and were less likely to not be in the labor force for retirement reasons.

Finally, we explore several potential mechanisms for our findings. While we cannot rule out supply-side explanations for reductions in employment, such as caregiving needs or virus fears keeping people out of employment, we also find evidence of demand-side explanations, such as employment reductions resulting from business closures and statewide shutdown policies. We do not find evidence that disability applications changed differentially based on state shutdown policies, degree of teleworkable jobs, or internet connectivity; however, survey data reinforce the fact that a non-trivial fraction of individuals decided not to apply for Social Security benefits as a result of the pandemic (United States Census Bureau, 2021). This rate was higher among those receiving unemployment insurance, suggesting that expanded Unemployment Insurance (UI) benefits resulting from the Coronavirus Aid, Relief, and Economic Security (CARES) Act passed in March 2020 and the American Rescue Plan passed in March 2021 may have reduced incentives to apply for disability insurance or claim early retirement benefits.

We contribute to a large and growing literature examining the negative labor market consequences of the COVID-19 pandemic (e.g., Bartik et al. (2020), Cajner et al. (2020), Coibion, Gorodnichenko and Weber (2020), Forsythe et al. (2020)). Our paper extends this literature by investigating how COVID-19 impacted labor market outcomes among the population age 50-70, as well as applications to Social Security's disability and retirement programs, which to our knowledge have not been examined in prior work. 
In addition, our research adds to work on the effects of recessions on older and disabled workers more generally, and allows a comparison of how older workers fared in the COVID-19 recession relative to prior recessions. Prior research finds that when recessions occur near the time of retirement, older workers are more likely to leave the labor force and collect Social Security sooner (Coile and Levine, 2007, 2011). Munnell and Rutledge (2013) document widespread effects of the Great Recession on Social Security, including increases in early retirement claims and disability applications. Other work has found that older workers delay retirement in an effort to recover lost earnings and wealth (Helppie McFall, 2011; Chan and Stevens, 1999; Gustman, Steinmeier and Tabatabai, 2010; Goda, Shoven and Slavov, 2011).

A large existing literature has found that disability claiming through SSI and SSDI is sensitive to economic conditions and the generosity of other related public programs, such as UI (Stapleton et al., 1998; Autor and Duggan, 2003; Coe, Haverstick et al., 2010; Cutler, Meara and Richards-Shubik, 2012; Maestas, Mullen and Strand, 2015, 2018; Schmidt, 2012; Black, Daniel and Sanders, 2002; Charles, Li and Stephens Jr, 2018). These studies generally find that higher rates of unemployment lead to larger numbers of applications for SSI and SSDI, increasing both processing costs and benefit obligations substantially. Although more generous UI benefits are also associated with reduced SSDI claiming (Lindner, 2016), the expiration of UI benefits did not lead to meaningful increases in SSDI applications during the Great Recession (Mueller, Rothstein and Von Wachter, 2016).

Our results support a literature showing that the most economically vulnerable likely experienced the greatest negative economic impact from the pandemic. Prior studies have documented that economic impact of the pandemic particularly affected employment among the oldest workers (Bui, Button and Picciotti, 2020; Gupta et al., 2020), the youngest workers (Montenovo et al., 2020), Hispanic and Black workers (Clark, Lusardi and Mitchell, 2020; Montenovo et al., 2020), immigrant men (Borjas and Cassidy, 2020), women (Alon et al., 2020; Bui, Button and Picciotti, 2020; Clark, Lusardi and Mitchell, 2020; Montenovo et al., 2020), and lower wage or income workers (Bartik et al., 2020; Chetty et al., 2020; Clark, 
Lusardi and Mitchell, 2020). Other studies have documented that the negative economic effects of the pandemic are not only acutely larger in magnitude for more vulnerable populations, but also reverse more slowly with reopening policies than for other worker groups (Cheng et al., 2020). In addition, evidence prior to the pandemic shows that disability applicants with low education and earnings levels are disproportionately affected by Social Security field office closures (Deshpande and Li, 2019) and that reducing transaction costs

for disability insurance benefits can lead to higher levels of applications (Foote, Grosz and Rennane, 2019).

Finally, our study also expands recent work using Google Trends to identify real-time internet search behavior that could be predictive of future population-level outcomes. Recent work by Gupta et al. (2020) and Bacher-Hicks, Goodman and Mulhern (2021) use Google Trends to identify effects of COVID-19 on unemployment insurance claiming behavior and inequality in online schooling across households, respectively. Our paper adds to this literature by analyzing Google Trends search indices for disability, retirement, and Social Security, which complements our analysis using application counts.

\section{Background}

In the United States, a variety of benefits are available to older and disabled adults in the form of Supplemental Security Income (SSI), Social Security Disability Insurance (SSDI), and Social Security retirement income. Whether individuals choose to access these programs depends on the benefits from the program as well as the benefits from not applying for these programs.

The primary disability support programs in the U.S. are SSI and SSDI, which offer individuals with qualifying disabilities income support as well as health insurance and other benefits. A disability must be severe enough to prevent participation in "substantial gainful activity," i.e., earning more than approximately $\$ 1,260$ per month in 2020 , and must be 
terminal or expected to last for at least 12 months. In order to qualify for SSI, individuals must have assets of less than $\$ 2,000$ for an individual or $\$ 3,000$ for a couple. For SSDI, individuals must have worked long enough to qualify, approximately 25 percent of their adult life and 5 of the last 10 years before the onset of disability. ${ }^{1}$ Most individuals who qualify for SSDI do not qualify for SSI because the SSDI benefits exceed the income limit for SSI eligibility. Average SSI payments for individuals were $\$ 549$ per month in 2019 (SSA, 2019), while average SSDI payments for individuals were $\$ 1,236$ (CBPP, 2019). Medicaid coverage is immediate for SSI recipients in most states, while Medicare coverage begins for SSDI beneficiaries after a 24-month waiting period. ${ }^{2}$ Because age is correlated with disability, we expect near-elderly individuals are more likely to be on the margin between claiming and not claiming disability than younger individuals. In addition, near-elderly individuals will be more likely to have the work history necessary to qualify for SSDI. Because of their increased vulnerability to COVID-19 and a higher likelihood of other health conditions, health insurance coverage offered through disability programs may be differentially more attractive to older workers than to younger workers, further increasing the likelihood of applying for disability among the near-elderly.

In order to be eligible for retirement benefits, individuals (born 1929 or later) must have worked at least 10 years. Eligibility for full retirement benefits ranges from 66 to 67 years old, depending on the birth cohort, and early retirement benefits can be claimed at a reduced rate as early as age 62 . Benefits can be as high as 75 percent of average wages for very low earners, and spouses and dependent children also receive benefits. ${ }^{3}$

In response to the COVID-19 pandemic, a variety of economic stimulus payments and expanded unemployment benefits were made available, decreasing the relative benefit of applying for disability or retirement. Subject to an income cap, all Americans, even those whose employment status was unaffected, were eligible for economic stimulus payments.

\footnotetext{
${ }^{1}$ If the qualifying disability is blindness, individuals can earn up to $\$ 2,110$ per month in 2020 .

${ }^{2}$ Social Security Disability Benefits. https://www.ssa.gov/benefits/disability/. Accessed 07/09/20.

${ }^{3}$ Social Security Administration: Retirement Benefits. ssa.gov. Accessed 01/27/2021.
} 
For those whose employment was negatively affected, the federal government supplemented state-provided unemployment benefit payments, added support for the self-employed, and extended the duration of unemployment benefit eligibility until September 1, 2021. For occupations ranging from food service to teachers, unemployment insurance income replacement rates exceeded pre-pandemic earnings, and therefore, expected retirement or disability income payments (Ganong, Noel and Vavra, 2020).

\section{Data}

We explore several different sources of data to assess how older workers are faring during the COVID-19 pandemic. First, we utilize public use microdata from the monthly IPUMS Current Population Survey (CPS) from January 2015 - March 2021 (Flood et al., 2020). We limit our analysis to those aged 50-70 at the time of survey, and utilize survey weights in all of our analysis. The monthly CPS is administered by the Census Bureau and is designed to measure employment in the civilian labor force using a probability-selected sample of about 60,000 households. ${ }^{4}$ The fieldwork is conducted during the calendar week that includes the 19th of the month, and the questions refer to activities during the prior week. Households cycle through the sample in the following way: 4 months in, 8 months out, 4 months in.

The CPS records one's labor force status as employed, unemployed, or not in the labor force. The unemployed category includes both those who are on layoff and those who are looking for employment. In addition, there is a category that denotes people who are employed but missed work or were at work part time during the survey reference week (employed-absent) which we analyze separately. Not in the labor force, or NILF, denotes those who are not employed and are not recently seeking work. ${ }^{5}$ People report being out of the labor force due to retirement, disability, or other (unspecified) reasons. In addition to labor force-related questions, the CPS also collects information on basic demographics,

\footnotetext{
${ }^{4}$ People in institutions, such as prisons, long-term care hospitals, and nursing homes are ineligible to be interviewed in the CPS.

${ }^{5}$ The CPS defines recently seeking work as those looking for work in the last four weeks.
} 
including age, sex, race, ethnicity, education, marital status and household size, whether someone is located in a metro area, and state and county of residence. ${ }^{6}$

Motivated by the difference in eligibility for claiming Social Security retirement benefits across our sample as well as different baseline levels of employment, we perform our analysis of the CPS separately in two age groups: 50-61-year-olds, and 62-70-year-olds. Tables 1 and 2 summarize, by age group, our control and outcome variables before and after COVID19 shutdowns began disrupting the U.S. economy in March 2020. Over the six years we examine, our dataset includes 2,504,444 total person-month observations $(1,505,301$ personmonth observations age 50-61, and 999,143 person-month observations age 62-70). These two groups do not vary greatly in their demographic characteristics aside from age; however, as shown in Table 2, their employment characteristics are substantially different, showing the exit from the labor market that is happening over these ages. For example, approximately two thirds of those aged 50-61 are employed at the time of survey, but only one third of 62-70-year-olds report being employed. This difference across the two groups is primarily offset by a shift out of the labor force for retirement.

We report the shares of the 50-61 and 62-70 population employed, employed but absent, unemployed, and not in the labor force for any reason over the 2015-2021 sample period in Figure 1. As is shown in the figure, in general, employment is trending upward over this period, with a sharp change occurring in March 2020. There is a great deal of seasonality in the data, particularly in the employed-absent category, with a substantial share reporting being employed but absent during the summer months, likely reflecting people not at work due to vacations. The employed-absent category also appears different in March 2020 relative to prior years, particularly for the 50-61 age group.

Figure 2 decomposes the share of the 50-61 and 62-70 population not in the labor force

\footnotetext{
${ }^{6}$ The CPS is known to suffer from non-response bias (Bollinger and Hirsch, 2013; Bollinger et al., 2019; Hokayem, Bollinger and Ziliak, 2015). This non-response bias may have changed with the pandemic. Particularly among lower income individuals, non-response was found to be worse during the 2020 CPS Annual Social and Economic Supplement (ASEC) than in prior years, with changes in response patterns by age, education, Hispanic origin, citizenship, and nativity (Rothbaum and Bee, 2020). Older adults appear to be over-represented in the 2020 CPS relative to prior years (Rothbaum and Bee, 2020).
} 
into three groups: those not in the labor force due to retirement, disability, or other reasons. As mentioned before, the share retired varies considerably for the older and younger subgroup, as shown in Figure 2a. In Figure 2b, we see that the share disabled is trending down over recent years for the 50-61-year-olds, but roughly constant for 62-70-year-olds. There is a visible drop after the start of the pandemic. We see the opposite pattern in Figure 2c, where the proportion reporting that they are not in the labor force for reasons other than disability or retirement is at an elevated level following the pandemic, especially for the 50-61 year old age group.

While the CPS provides the ability to perform individual-level analysis, it lacks direct measures of Social Security benefit claiming. We address this issue by supplementing our analysis with three additional sources of data. The first two are administrative datasets made publicly available by the Social Security Administration (SSA). The SSA State Agency Monthly Workload Data reports historical and current information about the processing of claims for disability benefits. The dataset includes the monthly numbers of claims for disability benefits that were referred for a disability determination to one of the 54 state agencies. We use data on initial claims for Supplementary Security Income (SSI), Social Security Disability Insurance (SSDI), and concurrent SSI and SSDI applications for each state and month between January 2015 and March 2021. This dataset defines months based on the number of administrative weeks rather than calendar month definitions, where each "month" is comprised of either four or five administrative weeks depending on how the days of the week fall in that month. Because the number of weeks in a month differs across calendar years, we first adjust the number of applications to represent the average number of applications each week. We then convert the average number of applications each week into an application rate per 100,000 people aged 20-64 using state-level population estimates for each year. The final dataset includes 3,825 state-by-month observations. We also analyze SSA Monthly Data for Retirement Insurance Applications which reports the number of national applications filed online and in total, from which we can back out the number of 
applications filed in person and by phone. However, these data are only available at the national level, so we are not able to see how these data vary by state, and thus have 76 observations (one for each month in our sample period). These data are also based on SSA reporting months, so we translate the monthly applications filed into the average weekly applications filed, and then convert the average number of applications each week into an application rate per 100,000 people aged 60-69 using national population estimates for each year.

Figure 3 displays national trends in the weekly disability and retirement applications rate over our sample period. Overall, the average number of applications trends fairly flat over the period we examine. The average weekly application rate in the pre-COVID era is 25 applications per 100,000 people aged 25-64 for all disability applications, with approximately a quarter coming from concurrent applications and the remainder split between SSDI only and SSI only. For retirement applications, there are approximately 145 applications per 100,000 people aged 60-69, with about half filed via the internet and half filed through other channels. There is a noticeable shift to online applications following COVID in the raw data.

Our final source of data comes from Google Trends, which makes measures of search intensity publicly available nationally and by state on a monthly or weekly basis. Search intensity is a measure of the fraction of a given area's Google searches that are for a particular set of search terms, and higher search intensity corresponds to higher search volumes if overall search volumes are relatively constant over time. ${ }^{7}$ In order to compare search intensity over time and across areas, it is important to pull data in a way that normalizes data relative to a particular state. We download data at the month by state level and focus on the broad search terms "disability," "retirement," and "Social Security" to enhance the reliability of the data. ${ }^{8}$ In order to ease interpretability, we take the logarithm of search intensity so that

\footnotetext{
${ }^{7}$ Data from Statista, a private firm, reports the total number of search queries by Google as 11.9, 12.7, 12.2 and 12.4 billion in January, April, July and October 2020, respectively, according to "Number of explicit core search queries powered by search engines in the United States as of October 2020," obtained from https://www.statista.com/statistics/265796/us-search-engines-ranked-by-number-of-core-searches/ on February 22, 2021. These data suggest that search volumes did not change markedly over the pandemic.

${ }^{8}$ See Appendix A.1 for additional details regarding the methods used to obtain the Google Trends data
} 
our estimates can be interpreted as percent changes. Our total number of observations is 3,825. Figure 4 displays log search intensity data from Google Trends for each of our three search terms. All three slightly trend upwards with a break in trend occurring at the time of the COVID-19 shutdowns.

\section{Empirical Methods}

Our main analyses focus on changes in labor market outcomes for older workers and applications for Social Security disability or retirement benefits in response to the COVID-19 pandemic shock. We employ an event study framework to evaluate how our outcomes of interest change relative to the initial COVID-19 shock in March 2020 in a specification similar to Bacher-Hicks, Goodman and Mulhern (2021).

$$
\begin{aligned}
Y_{i s t}= & \sum_{k=-5}^{-1} \beta_{k} \times 1[e(t)=k]+\sum_{k=1}^{10} \beta_{k} \times 1[e(t)=k]+\theta \times 1[e(t)<-5] \\
& +\mu_{m(t)}+\delta t+\omega_{s}+\beta X_{i s t}+\varepsilon_{i s t} \\
Y_{s t}= & \sum_{k=-5}^{-1} \beta_{k} \times 1[e(t)=k]+\sum_{k=1}^{10} \beta_{k} \times 1[e(t)=k]+\theta \times 1[e(t)<-5] \\
& +\mu_{m(t)}+\gamma_{y(t)}+\omega_{s}+\varepsilon_{s t}
\end{aligned}
$$

In the specification above, $\mu_{m(t)}$ represents month indicators; $t$ represents a month-level time trend; $\omega_{s}$ represent state fixed effects; and $e(t)$ represents event time relative to February 2020, where the maximum value of $e(t)$ is 13, corresponding to March 2021. We use Equation 1a for our individual-level data from the CPS, where we add additional demographic controls such as age, race, Hispanic ethnicity, education, a metro area indicator, and household family size, and use Equation 1b for analyses using state-level Social Security data and Google Trends data. ${ }^{9}$ Data in months prior to $e(t)=-5$ are used to identify the month fixed

${ }^{9}$ We use year fixed effects rather than a month-level time trend for our specification with Social Security 
effects. The interpretation of the set of $\beta_{t}$ is the differences in the outcome compared to the same months in prior years presented in levels relative to February 2020 after accounting for a time trend and controlling for changes in the covariates. Thus, they represent deviations from calendar-predicted values relative to the actual deviation in February 2020. Standard errors are clustered at the state level.

Second, we collapse our event study in Equation 1 into a post-COVID indicator to estimate the average effect on outcomes in the post-pandemic period. We estimate the following specification:

$$
\begin{aligned}
& Y_{i s t}=\delta \text { PostCovid }_{i s t}+\mu_{m(t)}+\lambda t+\omega_{s}+\beta X_{i s t}+\varepsilon_{s t} \\
& Y_{s t}=\delta \text { PostCovid }{ }_{s t}+\mu_{m(t)}+\gamma_{y(t)}+\omega_{s}+\varepsilon_{s t}
\end{aligned}
$$

Here, $\delta$ represents the average overall post-COVID change in outcomes as compared to the same months in prior years. Therefore, $\delta$ represents the average of the coefficients on the event study indicator variables for the periods March 2020-March 2021, relative to February 2020 and earlier, after controlling for time trends, month and state fixed effects and other control variables when using individual data from the CPS.

\section{$5 \quad$ Results}

\subsection{CPS: Self-reported labor force participation}

We examine both an event study and a collapsed difference-in-difference specification for each of our outcomes across our different datasets. First, we estimate Equation 1a on CPS data to examine how employment outcomes differ for workers aged 50-61 and 62-70 each month relative to what would have been predicted during the COVID-19 pandemic shock assuming prior patterns of seasonality and trends would have continued. We normalize the data as we normalize applications by respective population counts which only vary at the year level. 
difference between the actual and counterfactual outcomes to zero in February 2020, so each month coefficient provides the deviation relative to the deviation in February 2020. In Figure 5, we see that in the months prior to March 2020, our outcomes among 50-70-year-olds did not differ substantially relative to prior year patterns, with a notable exception being higher levels of employment (and lower levels of labor force nonparticipation) in the months leading up to the pandemic for 62-70-year-olds. The gap between actual and counterfactual outcomes appears to be declining in the months leading up to February 2020.

Beginning in April 2020, employment declines sharply relative to the predicted employment rate to 10-15 percentage points lower than the counterfactual, with larger reductions for 50-61-year-olds. In the months following April 2020, employment slowly recovers before leveling off in June 2020 at a level about 5 percentage points lower than the counterfactual pre-COVID employment for 50-61-year-olds and 2 percentage points lower for 62-70-yearolds. By the end of the sample period, employment rates show signs of rebounding for both groups.

This decline in employment appears to be driven by different factors in the short- and longer-term. During the period of the largest drop in employment in April-May, the decline appears to be driven by increases in unemployment, people reporting they are employed but absent from work, and reductions in labor force participation. The larger reduction in employment for 50-61-year-olds relative to 62-70-year-olds is driven by larger deviations in unemployment, while the magnitudes of employed but absent and not in the labor force are similar across the two groups. The persistent reductions in employment in June-December are driven by unemployment for 62-70-year-olds and a combination of unemployment and exiting the labor force for 50-61-year-olds. Unlike unemployment, NILF appears to trend upward from June 2020 to early 2021, but is showing some signs of declining during the end of the sample period.

We collapse the post-COVID indicator variables into a single coefficient and estimate Equation 2a using our CPS sample and report the results in Table 3. Panel A reports results 
for 50-61-year-olds and Panel B reports results for 62-70-year-olds. In Panel A, we find that employment of workers aged 50-61 is 5.7 percentage points lower than would have been predicted from prior years, a reduction of approximately 8 percent relative to the pre-COVID mean level of employment over the period as a whole. Unemployment is 3.6 percentage points higher than the counterfactual, accounting for 63 percent of the employment decline. There is also a reduction in labor force participation over this period of 1.6 percentage points, representing a 6 percent decline, and 28 percent of the reduction in employment. The remainder reflects an increase in employed but absent of 0.5 percentage points.

In Panel B, we find results that are largely similar. The overall reduction in employment is 3.9 percentage points for 62-70-year-olds, smaller in magnitude than for 50-61-year-olds. However, because overall employment is lower among this group, the 3.9 percentage point reduction corresponds to an 11 percent reduction in employment relative to the pre-COVID mean. The largest component of this change is unemployment which increased by 1.9 percentage points relative to the counterfactual, representing 50 percent of the employment decline. The next largest component is NILF which saw a 1.6 percentage point increase over March 2020 - March 2021 relative to what would have been predicted. However, since the pre-COVID NILF rate for this group is larger, this increase represents a smaller 3 percent increase relative to the baseline.

In Table 4, we decompose NILF into its three components: retired, disabled, and other. Panel A reports results for 50-61-year-olds and Panel B reports results for 62-70 year olds. In both groups, we see that the overall increase in NILF is comprised of increases in labor force exits due to retirement and other reasons, but offset by reductions in labor force exits due to disability. Relative to the pre-COVID means, retirement increased by 0.3 percentage points and 1.2 percentage points among 50-61-year-olds and 62-70 year olds, respectively. While the increase is not substantial for 50-61 year olds, it represents a sizable share (30 percent) of the employment decline for 62-70-year-olds. Labor force exits due to reasons other than disability and retirement are elevated for both groups, 1.7 percentage points for 50-61 year 
olds and 0.8 percentage points for 62-70 year olds, accounting for 30 percent and 23 percent of the employment declines in each age group, respectively. Finally, these two increases were offset by declines in labor force exits due to disability of 0.4 percentage points in each group. This decline represents a 4 percent and 5 percent reduction among 50-61-year-olds and 62-70-year-olds, respectively.

People leaving the labor force due to other reasons comprise a substantial amount of the overall effect on NILF for both groups. Recent discussions regarding potential misclassification of workers suggests that unemployment may be higher than official statistics due to people being prevented from looking for employment by the pandemic, due to caregiving responsibilities, fear of the virus, and a lack of the return of service-sector jobs. ${ }^{10}$

We investigate the heterogeneity in our results by demographic characteristics, and our results are provided in Appendix B. Each table reports the results on the seven employment outcomes we examine where the Post-Covid indicator is interacted with a demographic characteristic, with the analysis performed separately for 50-61 year olds and 62-70 year olds as before. We examine how our results differ by sex, education, race/ethnicity, and living alone, where high education represents those who have completed college.

Our results indicate that, compared to men, women in the older age category experience larger declines in employment, which appear to be coming from increases in labor force nonparticipation. There is little evidence of significant differences across sex in the younger age group. When we split the sample by education, the lower-educated sample in the younger age group experiences larger employment declines and increases in unemployment that are similar in magnitude. In addition, the reduction in labor force exits due to disability are concentrated among the less educated. In the older age group, the employment decline is accounted for by different factors across education: for the higher education sample, a larger share of the decline is explained by labor force non-participation (either due to retirement

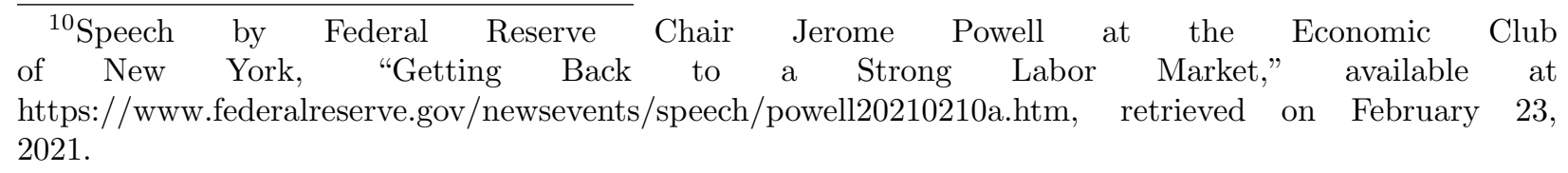


or other factors) while unemployment accounts for a larger share of the decline for those with lower levels of education. We find evidence that employment declines in the younger age group are larger for those reporting their race as other and those of Hispanic ethnicity, and both of these declines in employment are accompanied by increases in unemployment of similar magnitude. Our results also show that the declines in labor market exits due to disability are largest among Black and Hispanic people. Among the older age group, the employment decline is larger for those who report their race as other and both unemployment and labor market exits for reasons other than retirement or disability are also higher. Those reporting Hispanic ethnicity are much less likely to exit the labor force via retirement in this older age group. Finally, living alone is associated with a larger decline in labor market exits due to disability (in the younger age group) and a higher likelihood of exiting the labor force via retirement (in the older age group). In general, economically vulnerable groups were more prone to declines in employment, the reductions in disability were generally concentrated among groups that had relatively high baseline levels of labor force non-participation due to disability, and increases in retirement following the pandemic occurred to a greater extent among White and high education individuals.

\subsection{SSA Retirement and Disability Benefit Applications}

We next turn to a similar analysis of SSA data on applications for disability and retirement applications. Figure 6 displays the results of estimating Equation 1b using the SSA State Agency Monthly Workload Data. After the onset of the COVID-19 pandemic, applications for Social Security disability benefits drop significantly as seen in Figure 6a. Relative to prior years, there were $\sim 3$ fewer weekly total applications for SSI and/or SSDI per 100,000 people (aged 20 to 64) in March and April 2020 relative to what would have been predicted from

prior years. The dip in applications drops to nearly 8 fewer applications per 100,000 people in May 2020 relative to predicted levels, and the deviation hovers between 4 and 6 fewer applications per 100,000 people towards the end of our sample period. When we collapse the 
post-COVID months and estimate Equation 2b, we find that on average, total applications for SSDI and/or SSI declined by 3.8 applications per week, relative to a pre-COVID mean of 25.4, representing a 15 percent reduction.

In parts b-d of Figure 6, we break down total disability applications into three mutually exclusive groups, concurrent SSI and SSDI, SSDI only, and SSI only, to see which groups are driving this change. All subfigures are presented on the same y-axis scale to facilitate comparison across groups. Figure $6 \mathrm{~b}$ and $6 \mathrm{~d}$ highlight that a majority of the persistent decrease in applications is coming through the SSI channel. Turning to Table 5, SSI only applications decrease by 2.1 (or 22 percent) per 100,000 people, concurrent SSI and SSDI applications decrease by 1.1 (or 18 percent) per 100,000 people, and SSDI only applications decrease by 0.6 (6.5 percent) per 100,000 people over the March 2020 - March 2021 period overall. Together, these results suggest that the reduction in disability applications seen after COVID is primarily driven by a reduction in applications for SSI. The drop in SSI applications may reflect fewer people meeting the asset criteria due to stimulus payments.

When we instead focus on applications for Social Security retirement benefits, we do not find evidence of a significant change in total retirement applications, as shown in Figure 7 and Table 6. However, our results suggest that there was a movement away from applications filed offline (in field offices or by phone) towards applications filed via the internet. The coefficient estimate in Table 6 implies that 4.7 fewer applications per 100,000 people aged 60 to 69 were filed post-COVID relative to what would have been predicted using prior patterns; however, this effect is small relative to the pre-COVID baseline and indistinguishable from zero. When we split total applications into two groups, those filed via the internet and those filed through other channels, we see two offsetting effects. Following the onset of COVID19, we see a 20 percent increase in applications that are filed online and a corresponding reduction in applications filed offline, as would be expected due to fear of virus infection and field office closures. This suggests that while overall applications may not have changed, there may have been a shift in how individuals are applying for benefits during the pandemic 
that could persist into the future.

\subsection{Google Trends Searches for Retirement and Disability}

Finally, we examine changes in online search activity related to Social Security, retirement and disability by using data from Google trends. Figure 8a highlights a similar pattern to what we see in the SSA applications data and estimates of labor market exits due to disability. In the months following the COVID pandemic, more specifically from May 2020 onward, Google searches for "disability" decreased relative to what would have been predicted from prior years. Column 1 of Table 7 indicates that on average in the post-COVID pandemic period, there was on average a 7 percent decrease in search intensity for "disability." Data from the end of our sample period suggest that this reduction is shrinking in more recent periods.

A noticeable difference in Figure 8b as compared to 8a, is that searches for "retirement" dip immediately in March 2020 as opposed to a slightly more delayed response with "disability" searches. In addition, this lower search intensity is not consistent with a higher share of retirement benefits applied for online, an overall stable level of applications filed for retirement benefits in the post-COVID months, and increases in labor market exits due to retirement. Nonetheless, our results in Column 2 of Table 7 suggest that online searches for "retirement" declined by approximately 9 percent in the period after the start of the COVID-19 pandemic.

Figure 8c and Table 7 displays the results of our event study specification and collapsed regression on the search term "Social Security." While over the full post-COVID period, we find a small 0.4 percent reduction in search intensity for "Social Security," the event study results show a spike up in search intensity in April 2020 and March 2021. The spike in April 2020 coincides precisely with a statement from the U.S. Treasury that Social Security

beneficiaries who are typically not required to file tax returns would receive their economic 
impact payments from the CARES Act directly in their bank accounts. ${ }^{11}$ Similarly, the passage of the American Rescue Plan in March 2021 and the economic impact payments contained in the bill is likely to have led to a similar spike.

\section{Potential Mechanisms}

Our findings show evidence of large declines in employment among older workers between March 2020 and March 2021 relative to what we would have predicted absent the COVID-19 pandemic. Approximately two thirds of the employment declines are due to unemployment, while the remainder is due to people exiting the labor force. However, we do not currently see evidence that these labor force exits are accompanied by increases in applications for disability or retirement benefits; in the case of disability benefits, we find evidence of a decline in applications. In this section, we investigate several mechanisms for these findings.

Decreased employment and labor force participation could arise from labor supply-side factors, including choosing to not work due to fear of contracting COVID-19, difficulties working remotely, taking time out of the labor force to tend to caregiving needs made more difficult due to the pandemic, and reduced relative returns to working from extended unemployment benefits. ${ }^{12}$ On the demand side, mandated business shutdowns and stay-at-home orders, supply chain disruptions, cost-of-doing-business increases, and in some industries, a decline in consumer demand may have led employers to temporarily or permanently layoff workers.

To investigate the role of demand-side explanations, we utilize state-level measures of the degree a state was shut down as of May 2020, and construct the share of 50-70 year olds in each county who were employed in occupations that were not suitable for telework and

\footnotetext{
${ }^{11}$ Press Release, U.S. Treasury, "Social Security Recipients Will Automatically Receive Economic Impact Payments," April 1, 2020, retrieved from https://home.treasury.gov/news/press-releases/sm967 on January $28,2021$.

${ }^{12}$ Unemployment benefits have been extended through September 2021, which for some workers exceed wage replacement rates (Ganong, Noel and Vavra, 2020). Relief packages also included economic impact payments of $\$ 600$ in July 2020 and $\$ 300$ in December 2020 and March 2021.
} 
not deemed essential. ${ }^{13}$ We hypothesize that if demand-side factors are at play, employment reductions will be larger in areas where states instituted restrictive stay-at-home orders and places where there were larger shares of people employed in jobs that were vulnerable to job loss since they could not be performed remotely and were not deemed essential.

Our results indicate that reductions in employment were more pronounced in states where more of the economy was shut down, and in areas where a higher share of 50-70 year olds were employed in non-teleworkable and non-essential jobs (see Tables C.1 and C.2), suggesting the presence of demand-side factors in explaining employment reductions in this population.

We also summarize data from the Census Household Pulse Survey and categorize reasons for not working into supply- and demand-side factors as described in Appendix A. Figure D.1 displays the share of those not working citing retirement, supply-side factors, demand-side fators, and other factors between May 2020 and April 2021. The figure shows that demandside reasons appear to have been most prevalent during the first phase of the pandemic, but declined starting in the summer. Since then, both supply-side factors and retirement appear to have grown in magnitude. Among potential supply-side factors, a rational fear of COVID do not appear to be driving our results; our CPS results show that all states experienced improvements in labor force outcomes even while the pandemic worsened into the winter holiday season, and unreported results from the Pulse Survey show no major variation in fear of COVID as a reason for not working. ${ }^{14}$ In summary, these findings indicate that neither demand-side nor supply-side factors can be ruled out, and they are both contributing to the lower levels of employment seen during the 12 months since the start of the pandemic.

The extent to which declines in employment and labor force participation affect Social Security disability and retirement claiming depends on the demand for benefits and factors that could reduce the ability of the programs to supply these benefits. Demand for disability and retirement benefits may have decreased for several reasons. Expanded unemployment

\footnotetext{
${ }^{13}$ The source and methods used to construct these data is described in more detail in Appendix A.

${ }^{14}$ The lack of a correlation between labor market outcomes and disease exposure is supported by two papers showing increases in unemployment insurance claims did not vary with disease exposure (Rojas et al., 2020; Lin and Meissner, 2020).
} 
benefits and economic impact payments could have delayed the need for disability or retirement income or affected eligibility for means-tested SSI benefits. It could also be that a shift to remote work effectively decreased disability incidence if those with work limitations can more effectively work remotely than in person.

An additional factor that could affect demand for Social Security benefits is general uncertainty about the long-term effects of the pandemic on the economy, and the changing nature of work going forward. Even more so than past recessions, individuals may be taking a "wait-and-see" approach rather than making more permanent decisions, such as exiting the labor force and applying for Social Security benefits, which may be harder to reverse if conditions change. Stock market gains over the period examined may have also cushioned income losses for the subset of the population with stock portfolios, in contrast with prior recessions. These unique aspects of this recession may be leading to higher levels of unemployment in the short term, which could reverse into higher labor market exits (and Social Security benefits) in the future if people discontinue looking for work.

Among supply-side factors potentially affecting benefits, on March 17, 2020, SSA closed its offices to in-person applications, reducing applications to phone and online filing. Meanwhile, stay-at-home policies reduced internet access through, for example, closures of public libraries. ${ }^{15}$ In addition, restrictions on non-essential medical appointments were a typical component of state-level stay-at-home policies, limiting the ability of potential disability applicants to establish eligibility, with particularly negative impacts on the most vulnerable. Prior work showing that permanent office closures are associated with decreased disability applications, especially among more vulnerable populations(Deshpande and Li, 2019), support a supply-side explanation. Further supporting program access limiting applications, especially among the more vulnerable, the move to online-only applications also likely affected more vulnerable groups because lower income, less educated, Blacks and those living in a rural area have lower rates of internet access (Perrin and Atske, 2021).

\footnotetext{
${ }^{15} \mathrm{~A}$ recent Pew Research survey found that internet access rates were lower among older adults (Perrin and Atske, 2021).
} 
In an assessment of overall changes in demand for benefits, data from the Census Pulse Survey indicate that most individuals' likelihood of applying for Social Security and Medicare benefits did not change as a result of the pandemic. However, approximately 10 percent of 50-61 year olds and 7 percent of 62-70 year olds reported that they decided not to apply (Figure D.2), and this rate was higher among those who had applied for UI benefits (Figure D.3). To examine whether the shift to remote work may have reduced disability incidence, we examine indicators of disability as dependent variables in the monthly CPS, including difficulty with hearing, vision, memory, walking/climbing stairs, dressing/bathing, or doing errands. While these questions do not assess work-limiting disabilities, we do find some evidence of reductions in these self-reported disabilities following the start of the pandemic (Table E.1), suggesting that lower levels of disability may to some extent be explaining lower applications for disability benefits. With limited post-pandemic data, we cannot easily assess whether uncertainty is leading to a "wait-and-see" approach to disability and retirement claiming. However, Figure D.2 suggests that, at least in the short-run, few individuals decided to apply for Social Security benefits later than they would otherwise have applied, among respondents to the online Pulse Survey.

Among possible supply-side facts, stay-at-home policies and restrictions on non-essential medical appointments are unlikely to have led to a sustained reduction in disability applications given these delays were temporary and our event study figures show no evidence that applications increased after these bans were lifted. In addition, we find no evidence that disability applications declined differentially in areas where the stay-at-home orders were more restrictive (Table C.3) or in areas with a higher share of non-teleworkable and non-essential jobs (Table C.4). Using state-level measures of internet connectivity, we find little evidence to support that a lack of internet access drove the decline in disability applications - we find no evidence that application reductions were larger in areas with lower levels of internet connectivity (Table C.5). We cannot examine heterogeneity in retirement applications by geographic area because our data are at the national level, and we do not have demographic 
data for either disability or retirement applications, precluding us from exploring whether the most vulnerable were differentially affected.

In summation, our results suggest that demand-side factors may have outweighed supplyside factors in explaining the decline in Social Security applications. However, this overall assessment does not explain the large difference in magnitudes between our SSI and SSDI results. On the demand side, expanded unemployment benefits, greater ability to work remotely, or a healthy stock market do not explain the reduction in SSI applications, as SSI targets only those with little-to-no work history and few assets, i.e., one might have expected to see less of an effect on SSI application rates rather than more. With respect to supply-side factors, as with SSDI, stay-at-home orders and internet connectivity do not explain the declines. Three likely mechanisms remain. With respect to demand-side factors, it is possible that additional COVID-related relief may have boosted SSI applicants' net worth enough to disqualify them for benefits or that potential SSI applicants may be more likely than SSDI applicants to take a "wait-and-see" approach given uncertainty about the future. On the supply side, the difference could come from a greater impact on application rates from the closure of the SSA offices because SSI has an applicant pool arguably more vulnerable to office closures than SSDI.

We note that, in addition to the factors described above, a disproportionate number of older individuals and individuals with pre-existing conditions died from COVID-19, potentially reducing the population on the margin of program application. Any such effect is likely to be stronger among more vulnerable populations, such as potential SSI applicants (Adhikari et al., 2020). While we use population weights for the CPS employment outcomes, CPS survey response rates might have been impacted over the course of the pandemic in ways that may influence our findings. The Household Pulse Survey also relies on survey responses, and is furthermore only administered online, potentially leading to non-representative samples. Different response rates across subgroups and the Pulse survey's online focus might partially explain lower levels of applicants for retirement and disability benefits than we 
would otherwise expect, particularly for SSI.

\section{Conclusion}

The impact of COVID-19 on the labor market has been devastating, and workers at all stages of their careers have been affected by both supply- and demand-driven job losses. In this study, we analyzed how the pandemic and its ensuing economic recession impacted the labor market outcomes and Social Security application behavior of older workers. This group is of particular interest given the potential long-term implications of exiting the labor force and the potential spillover effects on Social Security benefits and associated expenditures.

Using survey data from the Current Population Survey, administrative data on Social Security applications, and Google Trends search intensity data, we show that employment of older workers fell substantially after the start of the COVID-19 pandemic. The fall in employment was driven primarily by increases in unemployment and labor force exits due to retirement (for individuals age 62-70) or labor force exits due to reasons other than retirement or disability (for individuals age 50-61). These changes were offset slightly by reductions in labor force exits due to disability. Evidence from Social Security administrative data indicates that disability applications fell, but that retirement applications were unchanged overall, and our Google Trends data suggest that search intensity for retirementand disability-related terms fell between March 2020 and March 2021 relative to what we would have expected prior to the pandemic.

We explore several mechanisms for our results, including factors related to labor supply and demand, as well as factors that may separate induce demand for Social Security benefits and/or limit the access of individuals to those benefits. Our results are generally consistent with reductions in labor demand, through stay-at-home orders and business closures, playing an important role in employment outcomes we examine, but we cannot rule out the presence of supply-side factors, such as concerns about caregiving, fear of contracting COVID-19, 
or enhanced unemployment benefits and economic impact payments, playing a role. Our findings are also consistent with individuals seeking benefits, particularly through the SSI program, encountering difficulties due to office closures and low internet access, and with UI potentially leading people to delay claiming benefits.

The different forces driving our results are important to understand due to their implications for longer-term projections, as well as the fiscal implications of the Social Security program. On the retirement side, actuarial factors that increase benefits for later retirement have been shown to be more than actuarially fair for a large share of the population (Shoven and Slavov, 2014), suggesting that earlier retirement could improve Social Security finances. For disability benefits, higher rates of applications and awards could increase the program's costs relative to its income. If part of the decline in benefits is driven by access issues or due to enhanced unemployment benefits, it is possible that there will be a surge in applications once these access issues subside, with no long-term fiscal implications. However, it is also possible that application levels persist at a lower level if disability incidence is lower due to telework options or if COVID-19 resulted in deaths among populations that were disproportionately on the margin of program application.

The long-term effects of the pandemic on labor markets and associated spillovers to disability and retirement claiming will remain uncertain until Social Security field offices reopen, extended unemployment benefits expire in September 2021, higher vaccination rates allow the economy to reopen fully, and the redesign of some workplaces and occupations to accommodate the flexibility to work from home converges. These ongoing changes highlight the importance of continuing to monitor changes in employment outcomes among older workers and spillovers onto the Social Security program going forward. 


\section{References}

Adhikari, Samrachana, Nicholas P. Pantaleo, Justin M. Feldman, Olugbenga Ogedegbe, Lorna Thorpe, and Andrea B. Troxel. 2020. "Assessment of CommunityLevel Disparities in Coronavirus Disease 2019 (COVID-19) Infections and Deaths in Large US Metropolitan Areas." JAMA Network Open, 3(7): e2016938-e2016938.

Alon, Titan M, Matthias Doepke, Jane Olmstead-Rumsey, and Michele Tertilt. 2020. "The impact of COVID-19 on gender equality." National Bureau of Economic Research Working Paper 26947.

Autor, David H, and Mark G Duggan. 2003. "The rise in the disability rolls and the decline in unemployment." The Quarterly Journal of Economics, 118(1): 157-206.

Bacher-Hicks, Andrew, Joshua Goodman, and Christine Mulhern. 2021. "Inequality in household adaptation to schooling shocks: Covid-induced online learning engagement in real time." Journal of Public Economics, 193: 104345.

Bartik, Alexander W, Marianne Bertrand, Feng Lin, Jesse Rothstein, and Matt Unrath. 2020. "Measuring the labor market at the onset of the COVID-19 crisis." National Bureau of Economic Research Working Paper 27613.

Black, Dan, Kermit Daniel, and Seth Sanders. 2002. "The impact of economic conditions on participation in disability programs: Evidence from the coal boom and bust." American Economic Review, 92(1): 27-50.

Bollinger, Christopher R., and Barry T. Hirsch. 2013. "Is Earnings Nonresponse Ignorable?" The Review of Economics and Statistics, 95(2): 407-416.

Bollinger, Christopher R., Barry T. Hirsch, Charles M. Hokayem, and James P. Ziliak. 2019. "Trouble in the tails? What we know about earnings nonresponse 30 years after Lillard, Smith, and Welch." Journal of Political Economy, 127(5): 2143-2185.

Borjas, George J, and Hugh Cassidy. 2020. "The adverse effect of the covid-19 labor market shock on immigrant employment." National Bureau of Economic Research Working Paper 27243.

Bui, Truc Thi Mai, Patrick Button, and Elyce G Picciotti. 2020. "Early Evidence on the Impact of Coronavirus Disease 2019 (COVID-19) and the Recession on Older Workers." Public Policy \& Aging Report, 30(4): 154-159.

Cajner, Tomaz, Leland Dod Crane, Ryan Decker, Adrian Hamins-Puertolas, and Christopher Johann Kurz. 2020. "Tracking labor market developments during the covid-19 pandemic: A preliminary assessment." Federal Reserve Board Finance and Economics Discussion Series 2020-030.

CBPP. 2019. "Chart Book: Social Security Disability Insurance." Center for Budget and Policy Priorities (CBPP). 
Chan, Sewin, and Ann Huff Stevens. 1999. "Employment and retirement following a late-career job loss." American Economic Review, 89(2): 211-216.

Charles, Kerwin Kofi, Yiming Li, and Melvin Stephens Jr. 2018. "Disability benefit take-up and local labor market conditions." Review of Economics and Statistics, 100(3): 416-423.

Cheng, Wei, Patrick Carlin, Joanna Carroll, Sumedha Gupta, Felipe Lozano Rojas, Laura Montenovo, Thuy D Nguyen, Ian M Schmutte, Olga Scrivner, Kosali I Simon, et al. 2020. "Back to business and (re) employing workers? Labor market activity during state COVID-19 reopenings." National Bureau of Economic Research Working Paper 27419.

Chetty, Raj, John N Friedman, Nathaniel Hendren, Michael Stepner, et al. 2020. "How did covid-19 and stabilization policies affect spending and employment? a new real-time economic tracker based on private sector data." National Bureau of Economic Research Working Paper 27431.

Clark, Robert L, Annamaria Lusardi, and Olivia S Mitchell. 2020. "Financial Fragility during the COVID-19 Pandemic." National Bureau of Economic Research Working Paper 28207.

Coe, Norma B, Kelly Haverstick, et al. 2010. "Measuring the spillover to disability insurance due to the rise in the full retirement age." Boston College Center for Retirement Research Working Paper, 21.

Coibion, Olivier, Yuriy Gorodnichenko, and Michael Weber. 2020. "Labor markets during the COVID-19 crisis: A preliminary view." National Bureau of Economic Research Working Paper 27017.

Coile, Courtney C, and Phillip B Levine. 2007. "Labor market shocks and retirement: Do government programs matter?" Journal of Public Economics, 91(10): 1902-1919.

Coile, Courtney C, and Phillip B Levine. 2011. "Recessions, retirement, and social security." American Economic Review, 101(3): 23-28.

Cutler, David M, Ellen Meara, and Seth Richards-Shubik. 2012. "Unemployment and disability: Evidence from the Great Recession." NBER Retirement Research Center Paper, No. NB 12-12.

Deshpande, Manasi, and Yue Li. 2019. "Who is screened out? Application costs and the targeting of disability programs." American Economic Journal: Economic Policy, 11(4).

Flood, Sarah, Miriam King, Renae Rodgers, Steven Ruggles, and J. Robert Warren. 2020. "Integrated Public Use Microdata Series, Current Population Survey: Version 8.0 [dataset]." 
Foote, Andrew, Michel Grosz, and Stephanie Rennane. 2019. "The Effect of Lower Transaction Costs on Social Security Disability Insurance Application Rates and Participation." Journal of Policy Analysis and Management, 38(1): 99-123.

Forsythe, Eliza, Lisa B Kahn, Fabian Lange, and David Wiczer. 2020. "Labor demand in the time of COVID-19: Evidence from vacancy postings and UI claims." Journal of public economics, 189: 104238.

Ganong, Peter, Pascal Noel, and Joseph Vavra. 2020. "US unemployment insurance replacement rates during the pandemic." Journal of Public Economics, 191: 104273.

Goda, Gopi Shah, John B Shoven, and Sita Nataraj Slavov. 2011. "What explains changes in retirement plans during the Great Recession?" American Economic Review, 101(3): 29-34.

Gupta, Sumedha, Laura Montenovo, Thuy Dieu Nguyen, Felipe Lozano-Rojas, Ian M Schmutte, Kosali Ilayperuma Simon, Bruce A Weinberg, and Coady Wing. 2020. "Effects of social distancing policy on labor market outcomes." NBER Working paper, , (w27280).

Gustman, Alan L, Thomas L Steinmeier, and Nahid Tabatabai. 2010. "What the stock market decline means for the financial security and retirement choices of the nearretirement population." Journal of Economic Perspectives, 24(1): 161-82.

Helppie McFall, Brooke. 2011. "Crash and wait? The impact of the Great Recession on the retirement plans of older Americans." American Economic Review, 101(3): 40-44.

Helppie-McFall, Brooke, and Joanne W. Hsu. 2020. "Financial profiles of workers most vulnerable to coronavirus-related earnings loss in the spring of 2020." FINANCIAL PLANNING REVIEW, 3(4): e1102.

Hokayem, Charles, Christopher Bollinger, and James P. Ziliak. 2015. "The Role of CPS Nonresponse in the Measurement of Poverty." Journal of the American Statistical Association, 110(511): 935-945.

Lindner, Stephan. 2016. "How do unemployment insurance benefits affect the decision to apply for social security disability insurance?" Journal of Human Resources, 51(1): 62-94.

Lin, Zhixian, and Christopher M Meissner. 2020. "Health vs. wealth? public health policies and the economy during covid-19." National Bureau of Economic Research Working Paper 27099.

Maestas, Nicole, Kathleen J Mullen, and Alexander Strand. 2015. "Disability insurance and the great recession." American Economic Review, 105(5): 177-82.

Maestas, Nicole, Kathleen J Mullen, and Alexander Strand. 2018. "The effect of economic conditions on the disability insurance program: Evidence from the great recession." National Bureau of Economic Research Working Paper 25338. 
Montenovo, Laura, Xuan Jiang, Felipe Lozano Rojas, Ian M Schmutte, Kosali I Simon, Bruce A Weinberg, and Coady Wing. 2020. "Determinants of disparities in COVID-19 job losses." National Bureau of Economic Research Working Paper 27132.

Mueller, Andreas I, Jesse Rothstein, and Till M Von Wachter. 2016. "Unemployment insurance and disability insurance in the Great Recession." Journal of Labor Economics, 34(S1): S445-S475.

Munnell, Alicia H, and Matthew S Rutledge. 2013. "The effects of the Great Recession on the retirement security of older workers." The Annals of the American Academy of Political and Social Science, 650(1): 124-142.

Perrin, Andrew, and Sara Atske. 2021. "7\% of Americans don't use the internet. Who are they?" Pew Research Center.

Rojas, Felipe Lozano, Xuan Jiang, Laura Montenovo, Kosali I Simon, Bruce A Weinberg, and Coady Wing. 2020. "Is the cure worse than the problem itself? Immediate labor market effects of COVID-19 case rates and school closures in the US." National Bureau of Economic Research Working Paper 27127.

Rosenthal, Ning, Zhun Cao, Jake Gundrum, Jim Sianis, and Stella Safo. 2020. "Risk Factors Associated With In-Hospital Mortality in a US National Sample of Patients With COVID-19." Journal of the American Medical Association, 3(12): e2029058.

Rothbaum, Jonathan, and Adam Bee. 2020. "Coronavirus Infects Surveys, Too: Nonresponse Bias During the Pandemic in the CPS ASEC." United States Census Bureau SEHSD WP2020-10.

Saletta, Michael, Matt Saletta, and Vivian Ho. 2020. "State Restrictions and the COVID-19 Death Rate." Baker Institute for Public Policy Report.

Schmidt, Lucie. 2012. "The Supplemental Security Income Program and Welfare Reform." Federal Reserve Board of Boston Public Policy Discussion Paper 12-3.

Shoven, John B., and Sita Nataraj Slavov. 2014. "Does it pay to delay social security?" Journal of Pension Economics and Finance, 13(2): 121-144.

SSA. 2019. "Annual Report of the Supplemental Security Income Program." Social Security Administration.

Stapleton, David, Kevin Coleman, Kimberly Dietrich, and Gina Livermore. 1998. "Empirical analyses of DI and SSI application and award growth." Growth in Disability Benefits: Explanations and Policy Implications, 31-92.

United States Census Bureau. 2021. "Household Pulse Survey Public Use Files [dataset]." 


\section{Figures and Tables}

Figure 1: Employment Outcomes for Ages 50-61 and 62-70, 2015-2021

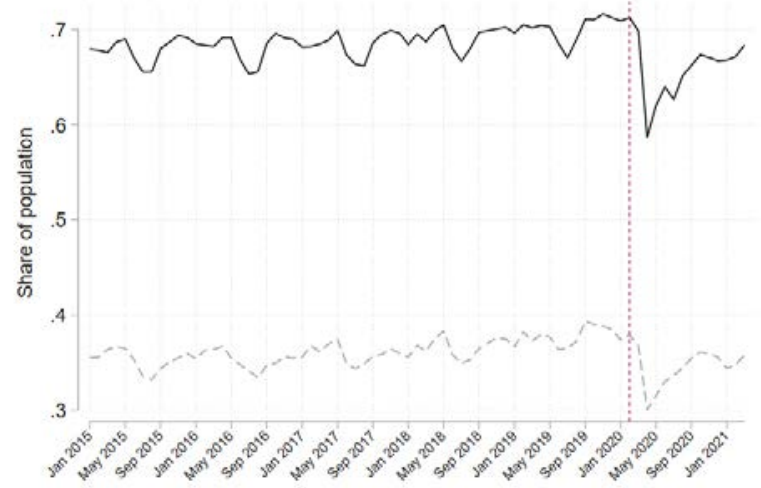

(a) Employed

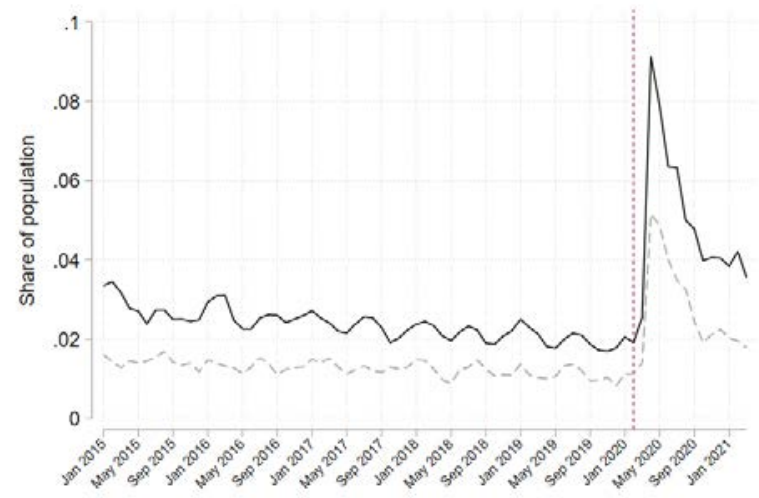

(c) Unemployed

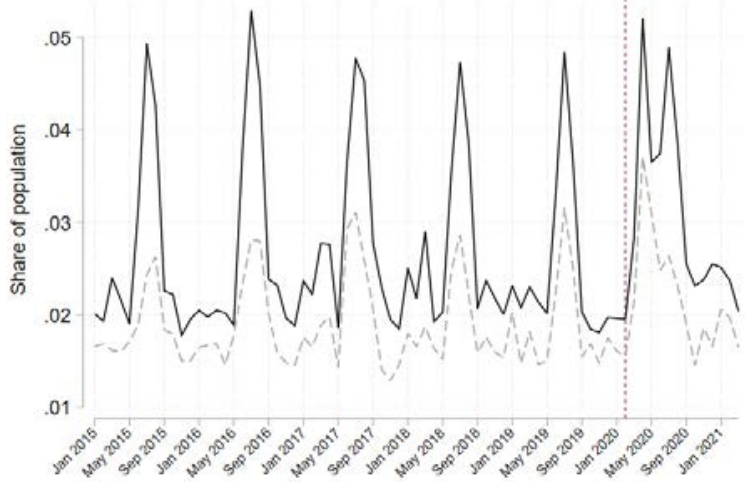

(b) Employed-Absent

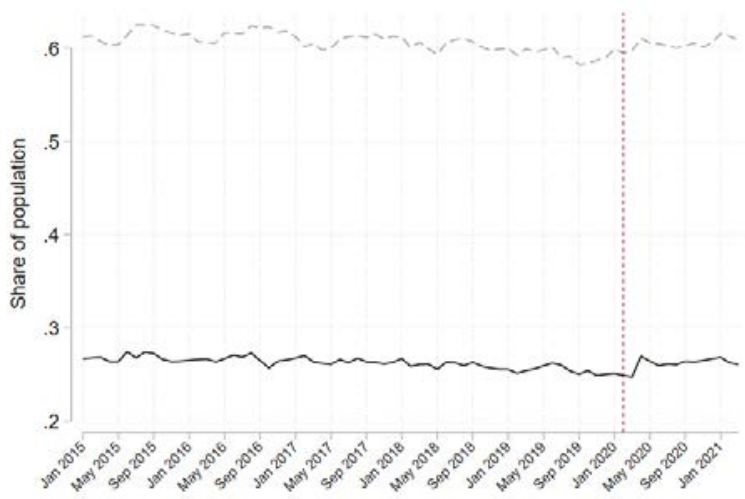

(d) NILF

$-50-61 \mathrm{yrs}$
$--62-70 \mathrm{yrs}$

Notes: Sample contains civilians ages 50-70 from the January 2015-March 2021 CPS living in the United States. Figures depict the share of individuals in an employment category in each month. Estimates are weighted using survey weights. 
Figure 2: NILF Outcomes for Ages 50-61 and 62-70, 2015-2021

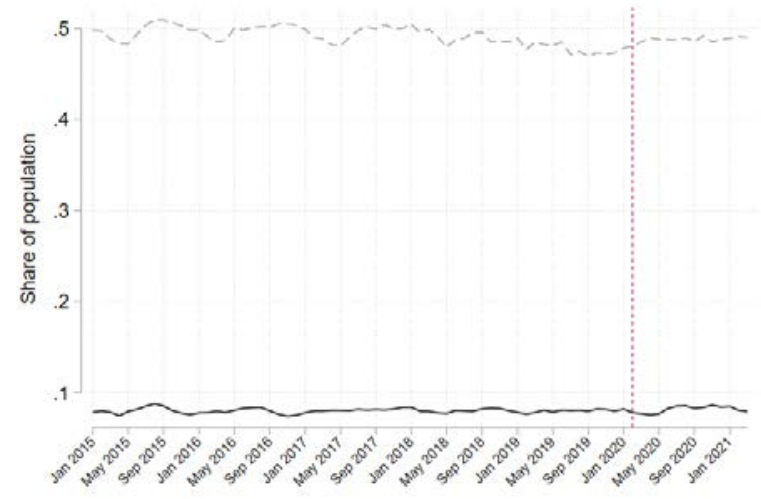

(a) Retired

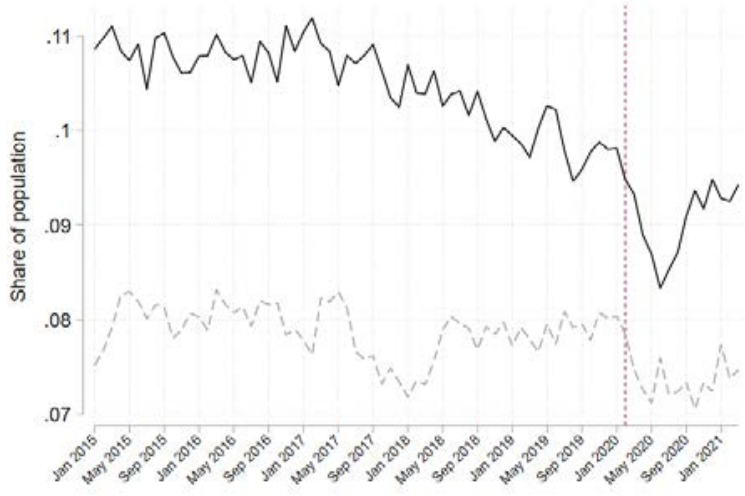

(b) Disabled

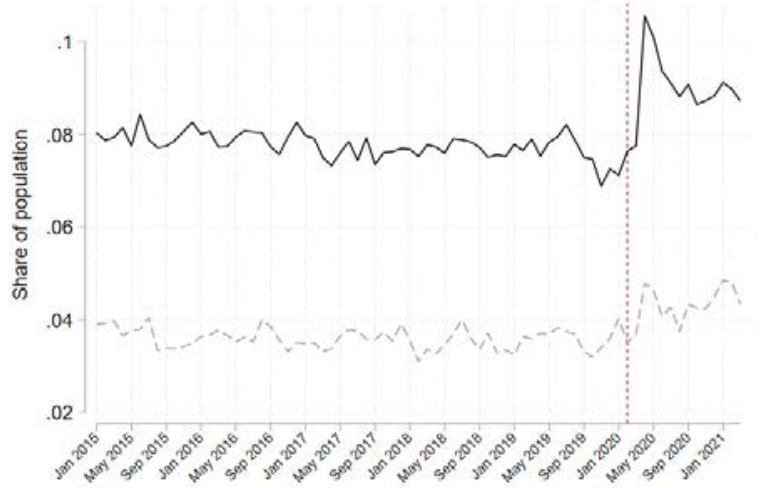

(c) Other

$$
\begin{aligned}
& -50-61 \text { yrs } \\
& --62-70 \text { yrs }
\end{aligned}
$$

Notes: Sample contains civilians ages 50-70 from the January 2015-March 2021 CPS living in the United States. Figures depict the share of individuals in an employment category in each month. Estimates are weighted using survey weights. 
Figure 3: Social Security Disability and Retirement Application Rates, 2015-2021

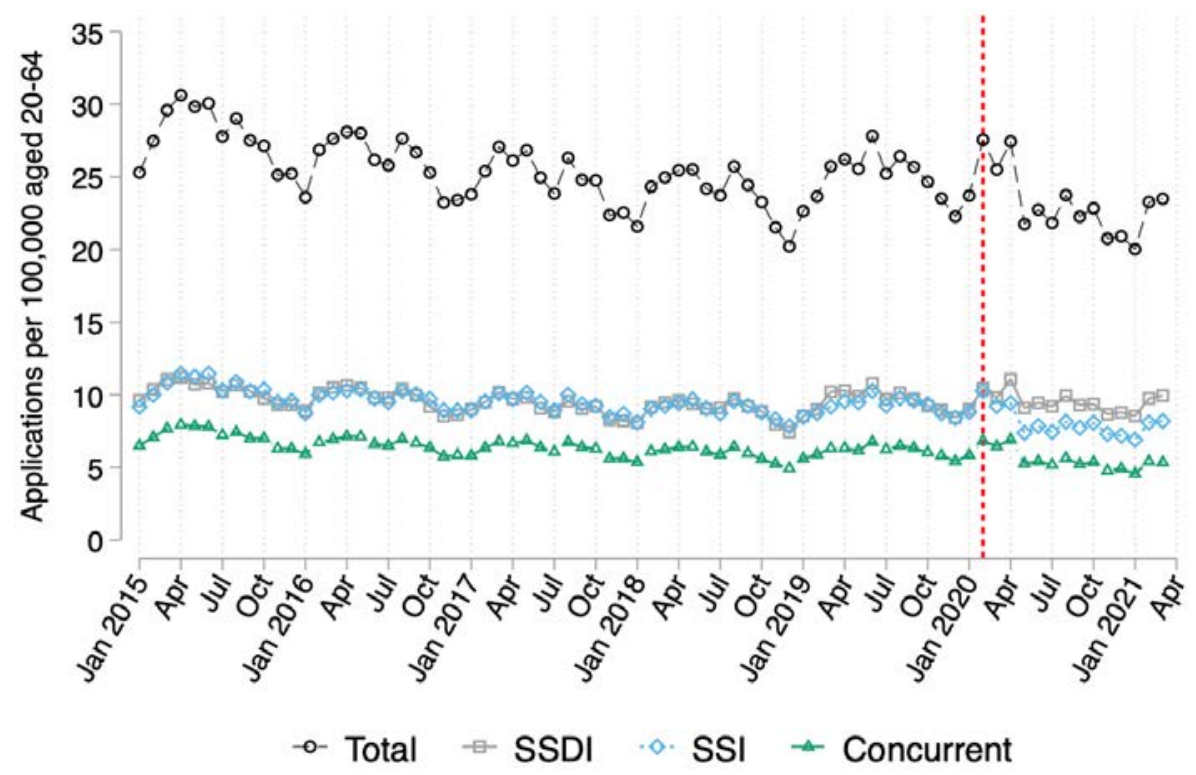

(a) Weekly Disability Applications Rate

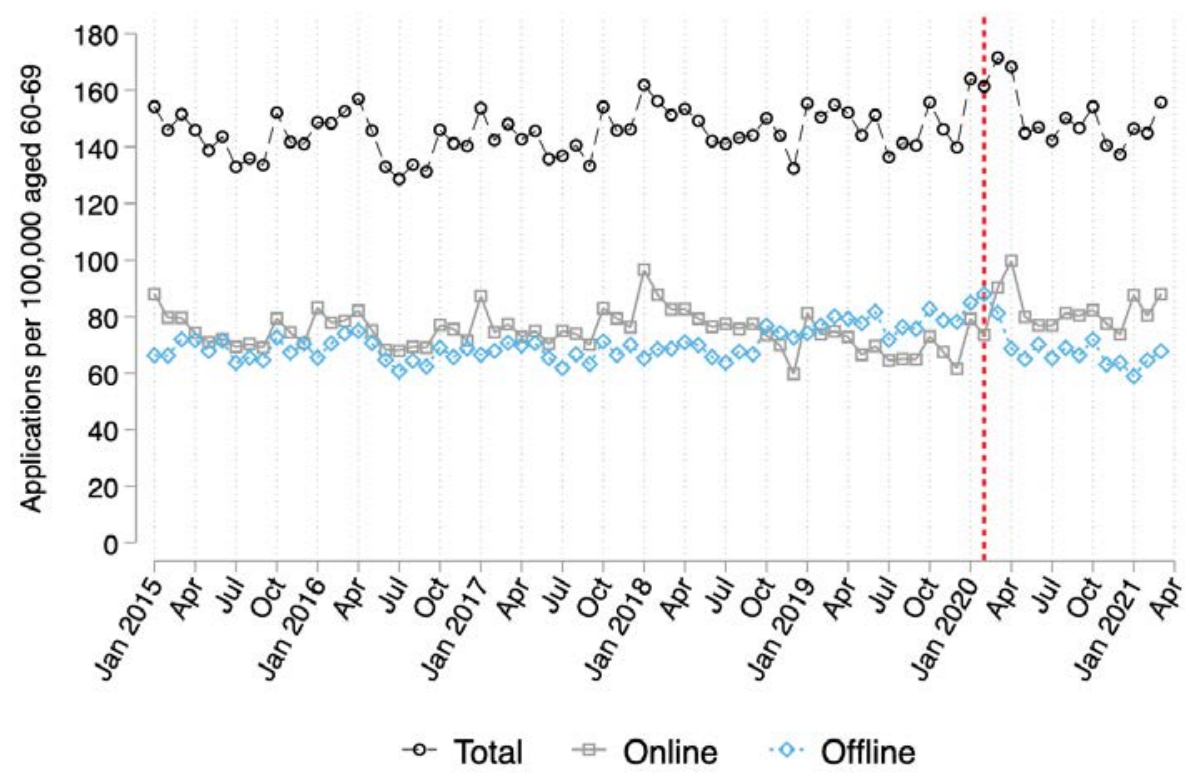

(b) Weekly Retirement Applications Rate

Notes: Panel (a) displays aggregated SSA State Agency Monthly Workload data and ranges from January 2015 to March 2021. Application rates are number of weekly applications per 100,000 people aged 20 to 64. Panel (b) displays aggregated SSA Monthly Data for Retirement Insurance Applications data and ranges from January 2015 to March 2021. Application rates are number of weekly applications per 100,000 people aged 60-69. 
Figure 4: Google Trends Search Intensity (Log) for Disability, Retirement, Social Security

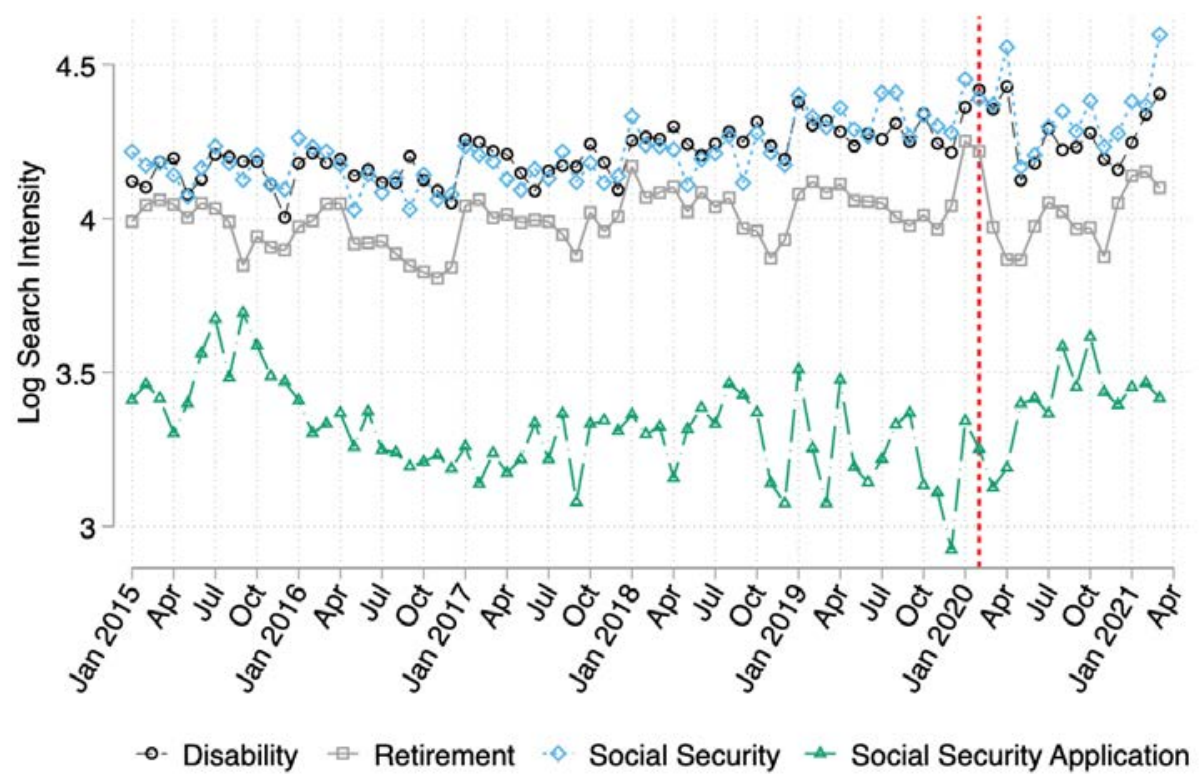

Notes: Figure displays log search intensity for Disability, Retirement, and Social Security using Google Trends. 
Figure 5: Event Studies of Employment Outcomes from the CPS Among 50-70 Year Olds

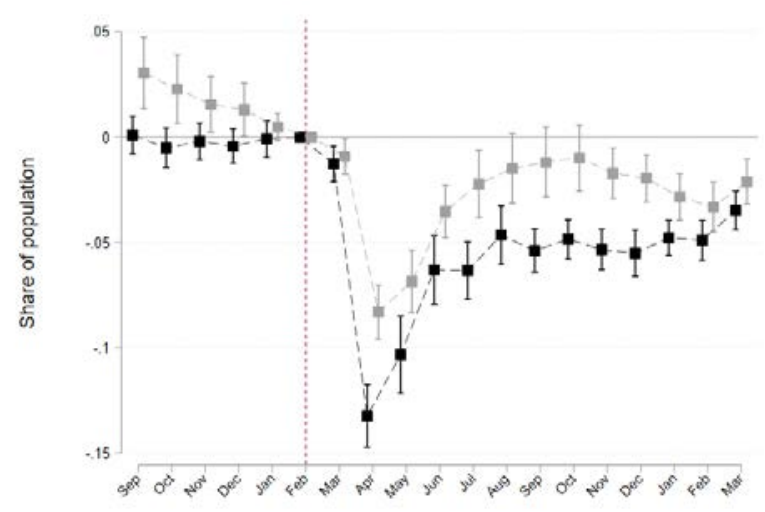

(a) Employed

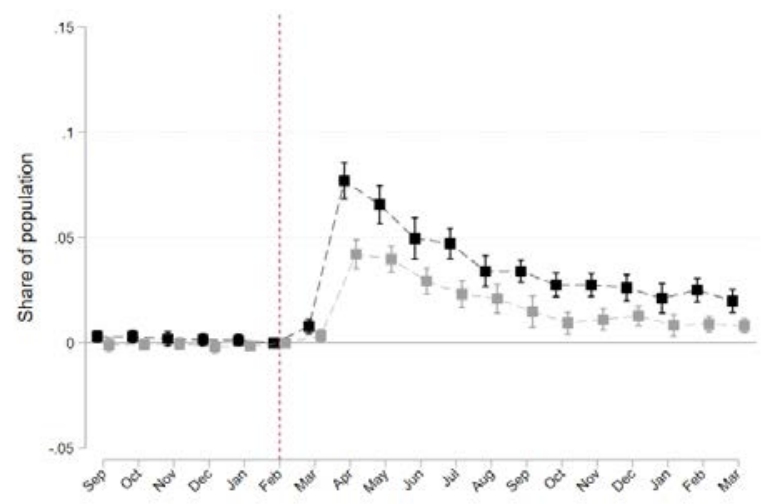

(c) Unemployed

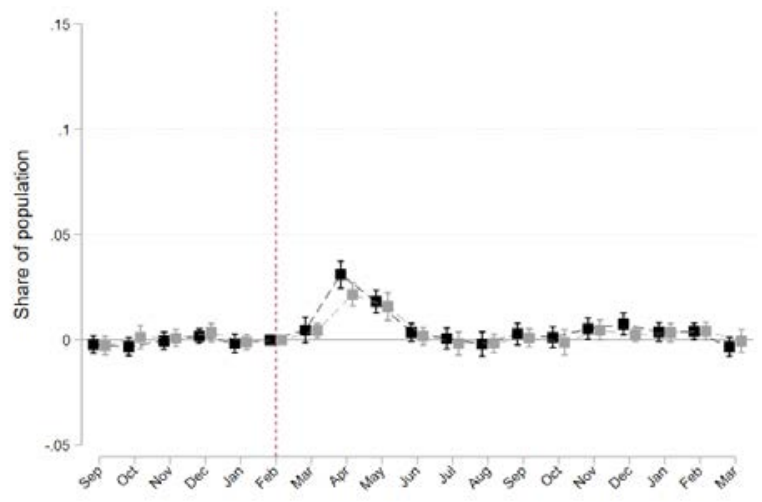

(b) Employed-Absent

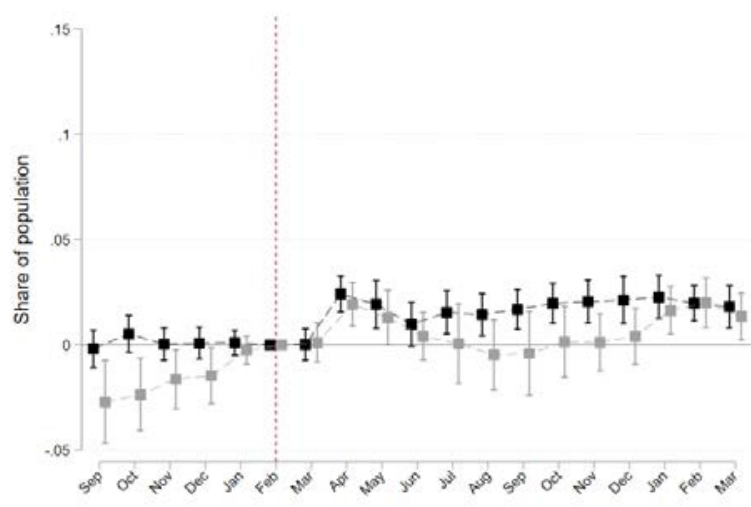

(d) NILF (Disability, Retired, Other)

Notes: Sample contains civilians ages 50-70 from the January 2015-March 2021 CPS living in the United States. Outcome variable is whether or not an individual is employed, employed but absent, unemployed, or not in the labor force. An individual is classified as employedabsent if they are absent from their job for a temporary reason during the survey reference week. Standard errors are robust and clustered at the state level. Estimates are weighted using survey weights and 95\% confidence intervals are shown. The event time is relative to February 2020. Regressions include a time trend, month and state fixed effects and adjust for age, sex, race, Hispanic ethnicity, education, and household family size. 
Figure 6: Event Study of Social Security Disability Applications

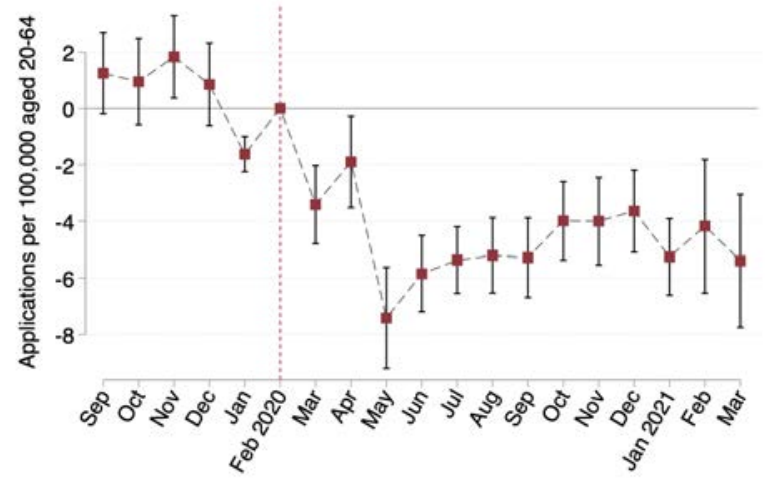

(a) Total SSI + SSDI

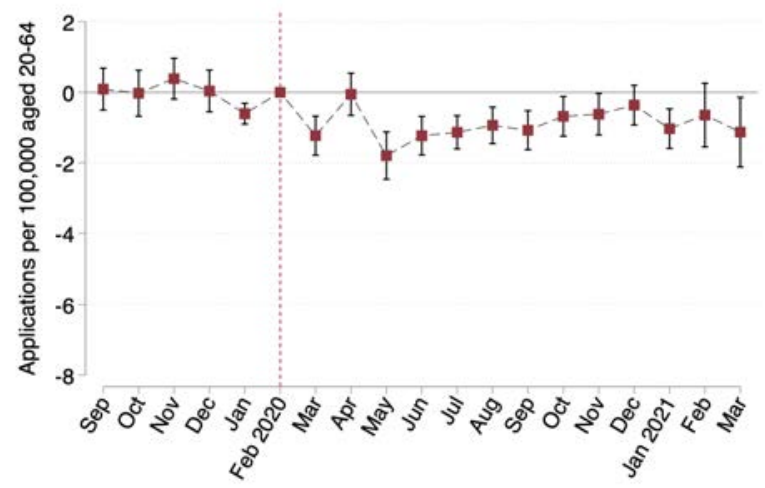

(c) SSDI Only

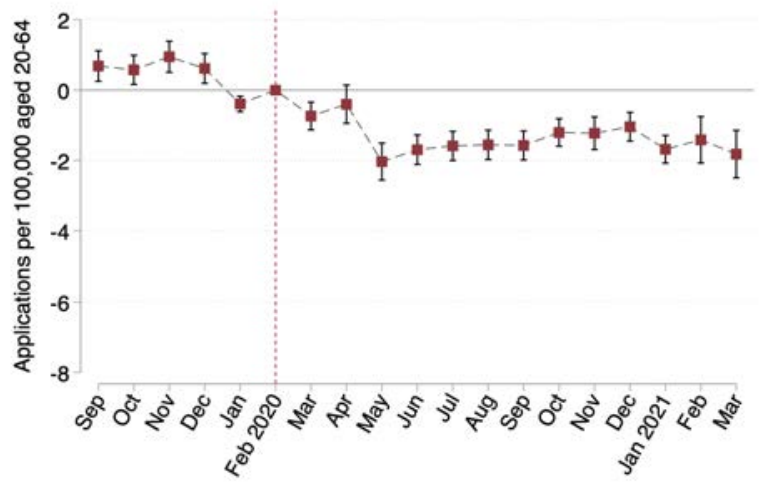

(b) Concurrent SSI and SSDI

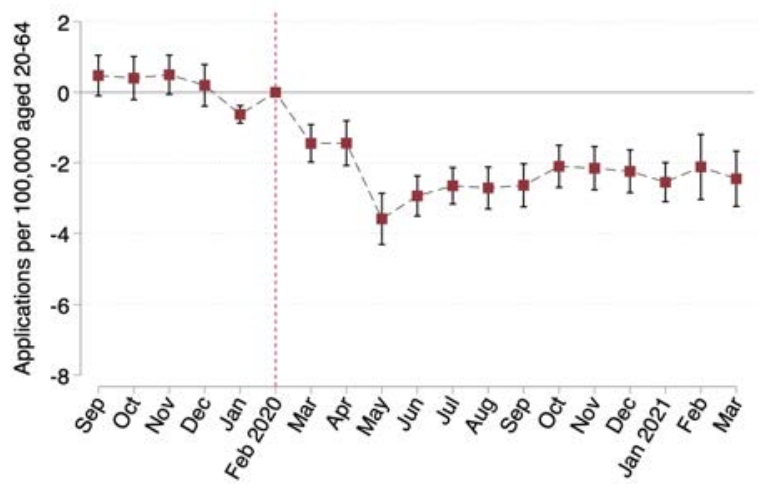

(d) SSI Only

Notes: Sample comes from the SSA State Agency Monthly Workload and ranges from January 2015 to March 2021. Outcome variable is weekly applications per 100,000 people aged 20 to 64 . Standard errors are robust and clustered at the state level. 95\% confidence intervals are shown. Regressions include month, year, and state fixed effects and event time relative to February 2020. 
Figure 7: Event Study of Social Security Retirement Applications

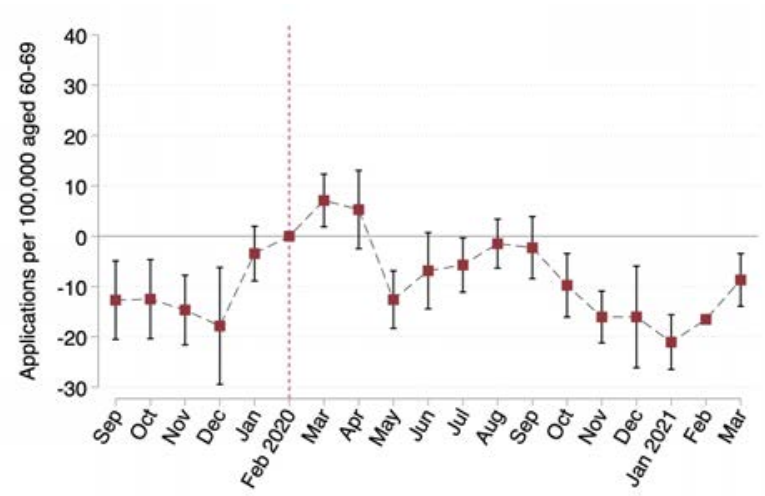

(a) Total Applications

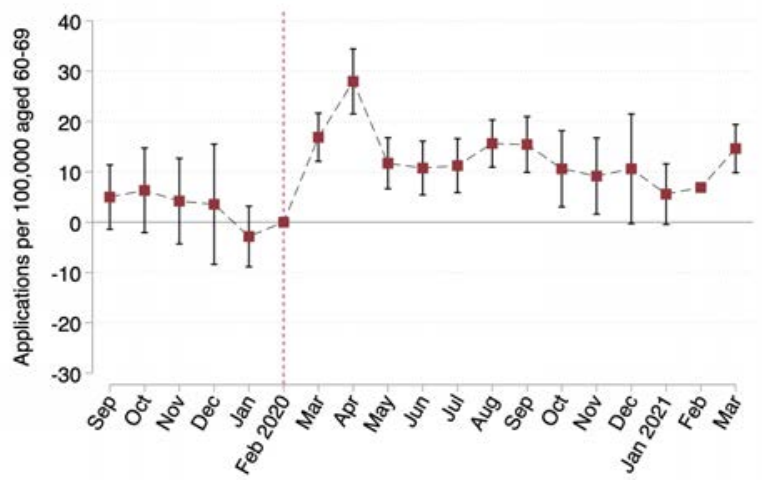

(b) Applications Filed via Internet

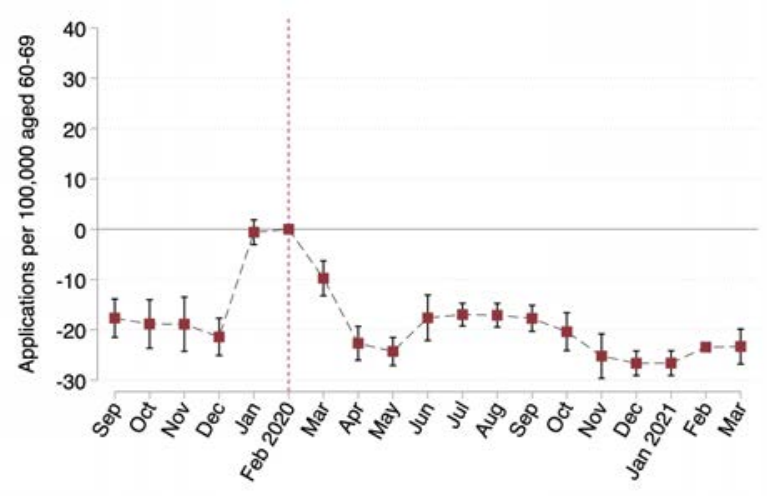

(c) Applications Filed Offline

Notes: Sample comes from the SSA Monthly Data for Retirement Insurance Applications and ranges from January 2015 to March 2021. Outcome variable is weekly applications per 100,000 people aged 60 to 69 . Standard errors are robust. 95\% confidence intervals are shown. Regressions include month and year fixed effects and event time relative to February 2020 . 
Figure 8: Event Study of Google Trends Search Terms

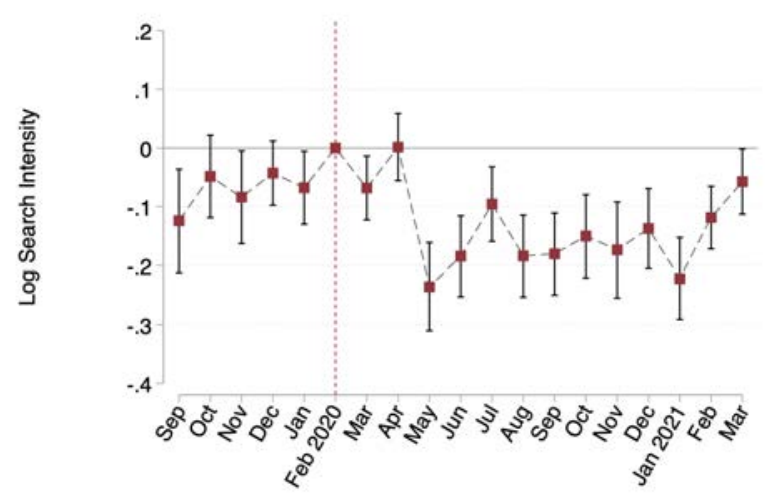

(a) Disability

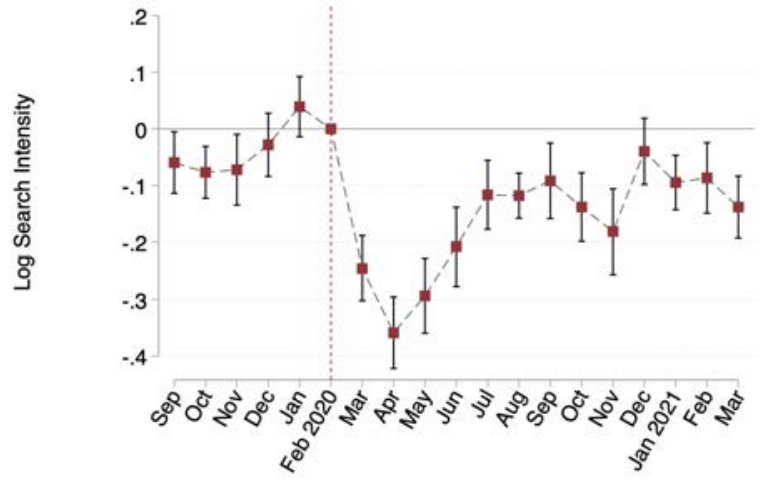

(b) Retirement

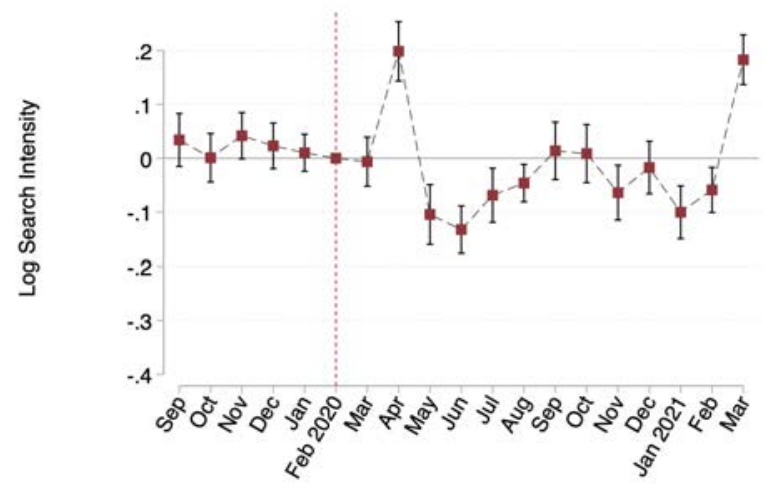

(c) Social Security

Notes: Sample contains search data from January 2015 to March 2021. Outcome variable is the logarithm of search intensity. Standard errors are robust and clustered at the state level. 95\% confidence intervals are shown. Regressions include a time trend, and month and state fixed effects and event time relative to February 2020. 
Table 1: CPS Demographic Summary Statistics

\begin{tabular}{|c|c|c|c|c|}
\hline & \multicolumn{2}{|c|}{ Ages 50-61 } & \multicolumn{2}{|c|}{ Ages $62-70$} \\
\hline & Pre-Covid & Post-Covid & Pre-Covid & Post-Covid \\
\hline Age & $\begin{array}{l}55.50 \\
(3.42)\end{array}$ & $\begin{array}{l}55.56 \\
(3.47)\end{array}$ & $\begin{array}{l}65.75 \\
(2.57)\end{array}$ & $\begin{array}{l}65.77 \\
(2.57)\end{array}$ \\
\hline Female & $\begin{array}{c}0.51 \\
(0.50)\end{array}$ & $\begin{array}{c}0.51 \\
(0.50)\end{array}$ & $\begin{array}{c}0.53 \\
(0.50)\end{array}$ & $\begin{array}{c}0.53 \\
(0.50)\end{array}$ \\
\hline White & $\begin{array}{c}0.80 \\
(0.40)\end{array}$ & $\begin{array}{c}0.79 \\
(0.41)\end{array}$ & $\begin{array}{c}0.82 \\
(0.38)\end{array}$ & $\begin{array}{c}0.81 \\
(0.39)\end{array}$ \\
\hline Black & $\begin{array}{c}0.12 \\
(0.33)\end{array}$ & $\begin{array}{c}0.12 \\
(0.33)\end{array}$ & $\begin{array}{c}0.11 \\
(0.31)\end{array}$ & $\begin{array}{c}0.11 \\
(0.32)\end{array}$ \\
\hline Other & $\begin{array}{c}0.08 \\
(0.27)\end{array}$ & $\begin{array}{c}0.09 \\
(0.28)\end{array}$ & $\begin{array}{c}0.07 \\
(0.25)\end{array}$ & $\begin{array}{c}0.07 \\
(0.26)\end{array}$ \\
\hline Hispanic & $\begin{array}{c}0.13 \\
(0.34)\end{array}$ & $\begin{array}{c}0.15 \\
(0.35)\end{array}$ & $\begin{array}{c}0.09 \\
(0.29)\end{array}$ & $\begin{array}{c}0.10 \\
(0.30)\end{array}$ \\
\hline$<$ High School & $\begin{array}{c}0.10 \\
(0.30)\end{array}$ & $\begin{array}{c}0.09 \\
(0.29)\end{array}$ & $\begin{array}{c}0.10 \\
(0.30)\end{array}$ & $\begin{array}{c}0.09 \\
(0.28)\end{array}$ \\
\hline High School & $\begin{array}{c}0.30 \\
(0.46)\end{array}$ & $\begin{array}{c}0.29 \\
(0.45)\end{array}$ & $\begin{array}{c}0.30 \\
(0.46)\end{array}$ & $\begin{array}{c}0.30 \\
(0.46)\end{array}$ \\
\hline Some College & $\begin{array}{c}0.16 \\
(0.37)\end{array}$ & $\begin{array}{c}0.15 \\
(0.35)\end{array}$ & $\begin{array}{c}0.17 \\
(0.38)\end{array}$ & $\begin{array}{c}0.17 \\
(0.37)\end{array}$ \\
\hline College+ & $\begin{array}{c}0.33 \\
(0.47)\end{array}$ & $\begin{array}{c}0.36 \\
(0.48)\end{array}$ & $\begin{array}{c}0.33 \\
(0.47)\end{array}$ & $\begin{array}{c}0.34 \\
(0.47)\end{array}$ \\
\hline Associates & $\begin{array}{c}0.11 \\
(0.31)\end{array}$ & $\begin{array}{c}0.11 \\
(0.31)\end{array}$ & $\begin{array}{c}0.10 \\
(0.30)\end{array}$ & $\begin{array}{c}0.11 \\
(0.32)\end{array}$ \\
\hline Disabled & $\begin{array}{c}0.13 \\
(0.33)\end{array}$ & $\begin{array}{c}0.11 \\
(0.31)\end{array}$ & $\begin{array}{c}0.18 \\
(0.39)\end{array}$ & $\begin{array}{c}0.17 \\
(0.37)\end{array}$ \\
\hline Married & $\begin{array}{c}0.65 \\
(0.48)\end{array}$ & $\begin{array}{c}0.65 \\
(0.48)\end{array}$ & $\begin{array}{c}0.65 \\
(0.48)\end{array}$ & $\begin{array}{c}0.65 \\
(0.48)\end{array}$ \\
\hline Divorced/Separated & $\begin{array}{c}0.19 \\
(0.39)\end{array}$ & $\begin{array}{c}0.19 \\
(0.39)\end{array}$ & $\begin{array}{c}0.18 \\
(0.38)\end{array}$ & $\begin{array}{c}0.18 \\
(0.38)\end{array}$ \\
\hline Widowed & $\begin{array}{c}0.04 \\
(0.19)\end{array}$ & $\begin{array}{c}0.03 \\
(0.18)\end{array}$ & $\begin{array}{c}0.09 \\
(0.29)\end{array}$ & $\begin{array}{c}0.09 \\
(0.29)\end{array}$ \\
\hline Single & $\begin{array}{c}0.12 \\
(0.32)\end{array}$ & $\begin{array}{c}0.13 \\
(0.33)\end{array}$ & $\begin{array}{c}0.08 \\
(0.27)\end{array}$ & $\begin{array}{c}0.09 \\
(0.29)\end{array}$ \\
\hline Household Size & $\begin{array}{c}2.61 \\
(1.36)\end{array}$ & $\begin{array}{c}2.65 \\
(1.37)\end{array}$ & $\begin{array}{c}2.16 \\
(1.13)\end{array}$ & $\begin{array}{c}2.17 \\
(1.14)\end{array}$ \\
\hline Lives Alone & $\begin{array}{c}0.18 \\
(0.38)\end{array}$ & $\begin{array}{c}0.17 \\
(0.38)\end{array}$ & $\begin{array}{c}0.23 \\
(0.42)\end{array}$ & $\begin{array}{c}0.23 \\
(0.42)\end{array}$ \\
\hline Lives in Metro Area & $\begin{array}{c}0.85 \\
(0.35) \\
\end{array}$ & $\begin{array}{c}0.86 \\
(0.35) \\
\end{array}$ & $\begin{array}{c}0.83 \\
(0.37) \\
\end{array}$ & $\begin{array}{c}0.84 \\
(0.37) \\
\end{array}$ \\
\hline Observations & 1286653 & 218648 & 838723 & 160420 \\
\hline
\end{tabular}

Notes: Sample contains civilians ages 50-61 and 62-70 from the January 2015-March 2021 CPS living in the United States. Share of each relevant demographic is listed and weighted using survey weights. Pre-Covid captures the mean outcome in the pre-period January 2015-February 2020. Post-Covid captures the mean outcome in the post-period March 2020-March 2021. 38 
Table 2: CPS Employment Summary Statistics

\begin{tabular}{|c|c|c|c|c|}
\hline & \multicolumn{2}{|c|}{ Ages 50-61 } & \multicolumn{2}{|c|}{ Ages $62-70$} \\
\hline & Pre-Covid & Post-Covid & Pre-Covid & Post-Covid \\
\hline Employed & $\begin{array}{c}0.688 \\
(0.463)\end{array}$ & $\begin{array}{c}0.659 \\
(0.474)\end{array}$ & $\begin{array}{c}0.363 \\
(0.481)\end{array}$ & $\begin{array}{c}0.344 \\
(0.475)\end{array}$ \\
\hline Employed-Absent & $\begin{array}{c}0.026 \\
(0.160)\end{array}$ & $\begin{array}{c}0.032 \\
(0.175)\end{array}$ & $\begin{array}{c}0.019 \\
(0.136)\end{array}$ & $\begin{array}{c}0.022 \\
(0.147)\end{array}$ \\
\hline Unemployed & $\begin{array}{c}0.024 \\
(0.152)\end{array}$ & $\begin{array}{c}0.047 \\
(0.212)\end{array}$ & $\begin{array}{c}0.013 \\
(0.112)\end{array}$ & $\begin{array}{c}0.028 \\
(0.165)\end{array}$ \\
\hline Not in Labor Force-Retired, Disabled, and Other & $\begin{array}{c}0.262 \\
(0.440)\end{array}$ & $\begin{array}{c}0.262 \\
(0.440)\end{array}$ & $\begin{array}{c}0.606 \\
(0.489)\end{array}$ & $\begin{array}{c}0.605 \\
(0.489)\end{array}$ \\
\hline Retired & $\begin{array}{c}0.080 \\
(0.271)\end{array}$ & $\begin{array}{c}0.084 \\
(0.277)\end{array}$ & $\begin{array}{c}0.491 \\
(0.500)\end{array}$ & $\begin{array}{c}0.488 \\
(0.500)\end{array}$ \\
\hline Disabled & $\begin{array}{c}0.105 \\
(0.306)\end{array}$ & $\begin{array}{c}0.094 \\
(0.292)\end{array}$ & $\begin{array}{c}0.079 \\
(0.270)\end{array}$ & $\begin{array}{c}0.073 \\
(0.261)\end{array}$ \\
\hline NILF-Other & $\begin{array}{c}0.078 \\
(0.268)\end{array}$ & $\begin{array}{c}0.084 \\
(0.278)\end{array}$ & $\begin{array}{c}0.036 \\
(0.186)\end{array}$ & $\begin{array}{c}0.043 \\
(0.204)\end{array}$ \\
\hline Observations & 1286653 & 218648 & 838723 & 160420 \\
\hline
\end{tabular}

Notes: Sample contains civilians ages 50-61 and 62-70 from the January 2015-March 2021 CPS living in the United States. Share of each employment status is listed and weighted using survey weights. An individual is classified as employed-absent if they are absent from their job for a temporary reason during the survey reference week. Pre-Covid captures the mean outcome in the pre-period January 2015-February 2020. Post-Covid captures the mean outcome in the post-period March 2020- March 2021. 
Table 3: Changes in Employment Outcomes Following COVID-19 Pandemic

A. 50-61-Year-Olds

\begin{tabular}{|c|c|c|c|c|}
\hline & $\begin{array}{c}(1) \\
\text { Employed }\end{array}$ & $\begin{array}{c}(2) \\
\text { Emploved-Absent }\end{array}$ & $\begin{array}{c}(3) \\
\text { Unemployed }\end{array}$ & $\begin{array}{c}(4) \\
\text { NILF }\end{array}$ \\
\hline Post Covid & $\begin{array}{c}-0.0571^{* * *} \\
(0.00314)\end{array}$ & $\begin{array}{l}0.00543^{* * *} \\
(0.000817)\end{array}$ & $\begin{array}{l}0.0357^{* * *} \\
(0.00256)\end{array}$ & $\begin{array}{l}0.0160^{* * *} \\
(0.00270)\end{array}$ \\
\hline Observations & 1505301 & 1505301 & 1505301 & 1505301 \\
\hline Pre-Covid Mean & 0.688 & 0.0263 & 0.0236 & 0.262 \\
\hline \multicolumn{5}{|c|}{ B. $62-70-Y e a r-O l d s$} \\
\hline & $\begin{array}{c}\text { (1) } \\
\text { Employed }\end{array}$ & $\begin{array}{c}(2) \\
\text { Employed-Absent }\end{array}$ & $\begin{array}{c}(3) \\
\text { Unemployed }\end{array}$ & $\begin{array}{c}(4) \\
\text { NILF }\end{array}$ \\
\hline Post Covid & $\begin{array}{r}-0.0387^{* * *} \\
(0.00369)\end{array}$ & $\begin{array}{l}0.00310^{* * *} \\
(0.000714)\end{array}$ & $\begin{array}{l}0.0192^{* * *} \\
(0.00167)\end{array}$ & $\begin{array}{l}0.0164^{* * *} \\
(0.00297)\end{array}$ \\
\hline Observations & 999143 & 999143 & 999143 & 999143 \\
\hline Pre-Covid Mean & 0.363 & 0.0188 & 0.0126 & 0.606 \\
\hline
\end{tabular}

Standard errors in parentheses

${ }^{*} p<0.10,{ }^{* *} p<0.05,{ }^{* * *} p<0.01$

Notes: Samples contains civilians ages 50-61 and 62-70 from the January 2015-March 2021 CPS living in the United States. Outcome variable is whether or not an individual is employed, unemployed, or not in the labor force due to disability, retirement, or another reason respectively. An individual is classified as employed-absent if they are absent from their job for a temporary reason during the survey reference week. Standard errors are robust and clustered at the state level. Estimates are weighted using survey weights. The Post-Covid estimate captures the change in employment outcome using January 2015-February 2020 as the pre-period and March 2020-March 2021 as the post-period. Regressions include a time trend, and month and state fixed effects, and adjust for age, sex, race, Hispanic ethnicity, education, and household family size. Pre-Covid means captures the mean of the dependent variable in the pre-period January 2015-February 2020. 
Table 4: Changes in NILF Following COVID-19 Pandemic

A. 50-61-Year-Olds

\begin{tabular}{|c|c|c|c|c|}
\hline & $\begin{array}{c}(1) \\
\text { NILF }\end{array}$ & $\begin{array}{c}(2) \\
\text { Retired }\end{array}$ & $\begin{array}{c}(3) \\
\text { Disabled }\end{array}$ & $\begin{array}{c}(4) \\
\text { Other }\end{array}$ \\
\hline Post Covid & $\begin{array}{l}0.0160^{* * *} \\
(0.00270)\end{array}$ & $\begin{array}{l}0.00332^{* *} \\
(0.00155)\end{array}$ & $\begin{array}{c}-0.00461^{* *} \\
(0.00187)\end{array}$ & $\begin{array}{l}0.0173^{* * *} \\
(0.00157)\end{array}$ \\
\hline Observations & 1505301 & 1505301 & 1505301 & 1505301 \\
\hline Pre-Covid Mean & 0.262 & 0.0799 & 0.105 & 0.0777 \\
\hline \multicolumn{5}{|c|}{ B. $62-70$-Year-Olds } \\
\hline & $\begin{array}{c}(1) \\
\text { NILF }\end{array}$ & $\begin{array}{c}(2) \\
\text { Retired }\end{array}$ & $\begin{array}{c}(3) \\
\text { Disabled }\end{array}$ & $\begin{array}{c}\text { (4) } \\
\text { Other }\end{array}$ \\
\hline Post Covid & $\begin{array}{l}0.0164^{* * *} \\
(0.00297)\end{array}$ & $\begin{array}{l}0.0117^{* * *} \\
(0.00368)\end{array}$ & $\begin{array}{c}-0.00415^{*} \\
(0.00218)\end{array}$ & $\begin{array}{c}0.00884^{* * *} \\
(0.00115)\end{array}$ \\
\hline Observations & 999143 & 999143 & 999143 & 999143 \\
\hline Pre-Covid Mean & 0.606 & 0.491 & 0.0789 & 0.0359 \\
\hline
\end{tabular}

Notes: Samples contains civilians ages 50-61 and 62-70 from the January 2015-March 2021 CPS living in the United States. Outcome variable is whether or not an individual is not in the labor force as well as each subcategory of NILF: disability, retirement, or another reason. Standard errors are robust and clustered at the state level. Estimates are weighted using survey weights. The Post-Covid estimate captures the change in employment outcome using January 2015-February 2020 as the pre-period and March 2020-March 2021 as the post-period. Regressions include a time trend, and month and state fixed effects, and adjust for age, sex, race, Hispanic ethnicity, education, and household family size. Pre-Covid means captures the mean of the dependent variable in the pre-period January 2015-February 2020. 
Table 5: Changes in Disability Applications Following COVID-19 Pandemic

\begin{tabular}{lcccc}
\hline \hline & $(1)$ & $(2)$ & $(3)$ & $(4)$ \\
& All & SSDI & SSI & Concurrent \\
\hline Post-Covid & $-3.797^{* * *}$ & $-0.606^{* * *}$ & $-2.083^{* * *}$ & $-1.108^{* * *}$ \\
& $(0.502)$ & $(0.190)$ & $(0.216)$ & $(0.153)$ \\
\hline$N$ & 3825 & 3825 & 3825 & 3825 \\
Pre-Covid Mean & 25.39 & 9.54 & 9.46 & 6.39 \\
\hline \hline
\end{tabular}

Robust and clustered (at state level) standard errors in parentheses

${ }^{*} p<0.10,{ }^{* *} p<0.05,{ }^{* * *} p<0.01$

Notes: Sample comes from the SSA State Agency Monthly Workload and ranges from January 2015 to March 2021. Outcome variables represent weekly applications per 100,000 people aged 20 to 64 . Other regressors (not shown) include month, year, and state fixed effects. Post-Covid refers to months March 2020 and later.

Table 6: Changes in Retirement Applications Following COVID-19 Pandemic

\begin{tabular}{lccc}
\hline \hline & $(1)$ & $(2)$ & $(3)$ \\
& Total & Filed via Internet & Filed offline \\
\hline Post-Covid & -4.652 & $14.92^{* * *}$ & $-19.57^{* * *}$ \\
& $(2.828)$ & $(2.271)$ & $(1.621)$ \\
\hline$N$ & 75 & 75 & 75 \\
Pre-Covid Mean & 145.35 & 74.75 & 70.60 \\
\hline \hline Robust standard errors in parentheses & \\
${ }^{*} p<0.10,{ }^{* *} p<0.05,{ }^{* * *} p<0.01$ &
\end{tabular}

Notes: Sample comes from the SSA Monthly Data for Retirement Insurance Applications and ranges from January 2015 to March 2021. Outcome variables represent weekly applications per 100,000 people aged 60 to 69 . Other regressors (not shown) include month and year fixed effects. Post-Covid refers to months March 2020 and later. 
Table 7: Changes in Google Search Intensity Following COVID-19 Pandemic

\begin{tabular}{lccc}
\hline \hline & $(1)$ & $(2)$ & $(3)$ \\
& Disability & Retirement & Social Security \\
\hline Post-Covid & $-0.0725^{* * *}$ & $-0.0916^{* * *}$ & -0.00412 \\
& $(0.013)$ & $(0.012)$ & $(0.010)$ \\
\hline$N$ & 3825 & 3825 & 3825 \\
Pre-Covid Mean & 4.208 & 4.002 & 4.206 \\
\hline \hline
\end{tabular}

Robust and clustered (at state level) standard errors in parentheses

${ }^{*} p<0.10,{ }^{* *} p<0.05,{ }^{* * *} p<0.01$

Notes: Sample contains search data from January 2015 to March 2021. Outcome variable is the logarithm of search intensity. Other regressors (not shown) include a time trend, and month and state fixed effects. Post-Covid refers to months March 2020 and later. 


\section{Appendix A: Data Appendix}

\section{A.1 Google Trends}

Google Trends provides access to a sample of actual search requests made to Google on data going back to 2004 and until 36 hours prior to the query. A sample of searches are used to generate the Google Trends data, and search data is normalized to allow comparisons. Specifically, each data point is divided by the total searches of the geography and time period to construct relative popularity, and the resulting value is scaled on a 0 to 100 range based on the term's popularity relative to all searches on all topics. The database that queries are made to filters some searches, such as duplicate searches by the same person over a short period of time.

We use the gtrends package in $\mathrm{R}$ to collect Google Trends data. The package allows one to obtain search intensity across a maximum of five different locations over a specified time range. Because the results of the query depend on the geographies used, we set one area as a reference area, and obtain data for the other areas by including four areas at a time with the designated reference area. This process ensures that the data from different queries can be pooled together and analyzed with relative search activity comparisons maintained.

The pool of searches that the search intensity is based on changes regularly, and there is no way to set a seed to exactly replicate the results from day to day. In addition, the choice of the reference state is arbitrary. We therefore perform several tests to ensure the data collected is reliable and can be replicated. We found that search intensity data is highly correlated from day to day and across reference states when there are fewer area-by-month combinations with zero search intensity, which occurs when broader search terms (such as "disability") are used, but are much less reliable when narrow search terms are used (such as "file for disability"), because the search intensity appears to be censored at zero for low search intensity area-by-month combinations.

In Tables A.1-A.3 below, we report the percentage of observations that are zero for 
various retirement-, disability- and Social Security-related search terms. Our main set of results reports analysis using the broadest search terms. However, we also analyze other search terms where at most 20 percent of the sample has observations censored at zero. These results are provided in Tables A.4-A.5, and provide similar findings as described in the main manuscript.

Table A.1: Percentage of observations that are zero - Retirement-related terms

\begin{tabular}{lc}
\hline \hline & $\%$ \\
\hline Retirement & 0.000 \\
Retire & 0.004 \\
Retirement Benefits & 0.159 \\
Retirement Application & 82.84 \\
Apply Retirement & 76.74 \\
Claim Retirement & 91.15 \\
Retirement Eligibility & 94.74 \\
Retirement Social Security & 12.36 \\
Retirement OR Retire & 0.00 \\
Retire Social Security & 52.53 \\
Retire Social Security OR Retirement Social Security & 10.02 \\
\hline \hline
\end{tabular}

Notes: Table provides share of observations between January 2015 and March 2021 that indicate zero search intensity for a state-month combination.

Table A.2: Percentage of observations that are zero - Disability-related terms

\begin{tabular}{lc}
\hline \hline & $\%$ \\
\hline Disability & 0.000 \\
Disabled & 0.0006 \\
Disability Benefits & 0.12 \\
Disability Application & 38.73 \\
Apply Disability & 28.35 \\
Claim Disability & 37.80 \\
Disability Eligibility & 85.08 \\
Disability Social Security & 3.70 \\
Disability OR Disabled & 0.00 \\
Disabled Social Security & 59.94 \\
Disabled Social Security OR Disability Social Security & 4.05 \\
\hline \hline
\end{tabular}

Notes: Table provides share of observations between January 2015 and March 2021 that indicate zero search intensity for a state-month combination. 
Table A.3: Percentage of observations that are zero - Social Security-related terms

\begin{tabular}{lc}
\hline \hline & $\%$ \\
\hline Social Security & 0.00 \\
'Social Security' & 0.00 \\
Social Security Benefits & 2.18 \\
Social Security Application & 24.65 \\
Apply Social Security & 18.36 \\
Claim Social Security & 45.67 \\
Social Security eligibility & 78.10 \\
\hline \hline
\end{tabular}

Notes: Table provides share of observations between January 2015 and March 2021 that indicate zero search intensity for a state-month combination.

Table A.4: Changes in Google Search Intensity Following COVID-19 Pandemic: Alternative Search Terms (Retirement)

\begin{tabular}{lccc}
\hline \hline & $(1)$ & $(2)$ & $(3)$ \\
& Retire & Retirement Benefits & Retirement OR Retire \\
\hline Post-Covid & $-0.117^{* * *}$ & -0.0346 & $-0.0861^{* * *}$ \\
& $(0.015)$ & $(0.029)$ & $(0.009)$ \\
\hline$N$ & 3806 & 3217 & 3825 \\
Pre-Covid Mean & 3.716 & 3.481 & 3.998 \\
\hline \hline
\end{tabular}

Robust and clustered standard errors in parentheses

${ }^{*} p<0.10,{ }^{* *} p<0.05,{ }^{* * *} p<0.01$

Notes: Sample contains search data from January 2015 to March 2021.

Table A.5: Changes in Google Search Intensity Following COVID-19 Pandemic: Alternative Search Terms (Disability)

\begin{tabular}{lccc}
\hline \hline & $(1)$ & $(2)$ & $(3)$ \\
& Disabled & Disability Benefits & Disability OR Disabled \\
\hline Post-Covid & $-0.0680^{* * *}$ & $-0.0773^{* *}$ & $-0.0667^{* * *}$ \\
& $(0.017)$ & $(0.030)$ & $(0.009)$ \\
\hline$N$ & 3823 & 3366 & 3825 \\
Pre-Covid Mean & 4.042 & 3.672 & 4.315 \\
\hline
\end{tabular}

Robust and clustered standard errors in parentheses

${ }^{*} p<0.10,{ }^{* *} p<0.05,{ }^{* * *} p<0.01$

Notes: Sample contains search data from January 2015 to March 2021. 


\section{A.2 Measures of Telework/Essential Work}

We employ the methodology described in the data appendix of Helppie-McFall and Hsu (2020) to create our measures of telework and essential work. Following their methodology, we are left with an occupation-level measure of whether a job is teleworkable and/or essential. We then merge these measures with our CPS sample data, still restricted to individuals aged 50-70 but also limited to sample year 2019. By examining 2019 and older workers in particular, we are able to determine the characteristics of relevant occupations across each state for the period immediately before the COVID-19 pandemic.

Once we merge in the occupation-level classifications with the each individual's occupation in the CPS, we divide individuals into three groups (1) teleworkable (2) non-teleworkable and essential and (3) non-teleworkable and non-essential. We collapse these classifications to the state-level and calculate the share of working individuals in each of the three groups. We consider states with a greater than median share in the third group (non-teleworkable and non-essential) to be affected by a "High Covid Shock".

\section{A.3 Measures of Shutdown}

To construct our measures of how shutdown a state was due to COVID-19, we draw from state-level data on relative openness compiled by WalletHub (see Table 1 in Saletta, Saletta and Ho (2020)). Specifically, we use the indices for openness from May 5, 2020 and split states into two groups, above and below median openness. We consider states below the median, with lower index values, to be more shutdown. Conversely, those above the median we consider to be less shutdown.

\section{A.4 Census Household Pulse Survey}

The 2020 Household Pulse Survey (HPS) was developed by the U. S. Census Bureau to measure the social and economic impact of the coronavirus (COVID-19) pandemic. The 
survey began data collection on April 23, 2020, soon after the beginning of the pandemic, to provide accurate and timely weekly estimates on a number of issues. The survey has been ongoing and some questions have been modified or added since the survey's inception. We utilize data from the first 29 weeks of the survey, ending with the survey fielded on April 28, 2021. ${ }^{16}$

We analyze the responses to questions regarding reasons for not working, and how the pandemic affected plans to apply for Social Security and Medicare benefits. First, the survey asks people born before 2002 about their employment status over the last 7 days: "In the last 7 days, did you do ANY work for either pay or profit?" Respondents were asked to select Yes or No. Those who responded no were then asked, "What is your main reason for not working for pay or profit?" Respondents were provided with 13 options:

1. I did not want to be employed at this time

2. I am/was sick with coronavirus symptoms

3. I am/was caring for someone with coronavirus symptoms

4. I am/was caring for children not in school or daycare

5. I am/was caring for an elderly person

6. I am/was sick (not coronavirus related) or disabled

7. I am retired

8. My employer experienced a reduction in business (including furlough) due to coronavirus pandemic

9. I am/was laid off due to coronavirus pandemic

10. My employer closed temporarily due to the coronavirus pandemic

\footnotetext{
${ }^{16}$ The survey was paused between July 21, 2020 and August 19, 2020, and between December 21,2020 and January 6, 2021.
} 
11. My employer went out of business due to the coronavirus pandemic

12. Other reason, please specify

13. I was concerned about getting or spreading the coronavirus

Item 13 was added in week 6, during the June 4, 2020 wave. After week 27 (March 17, 2021), the second and third options were combined into one option.

We characterize items 1-6 and 13 as supply-side factors, and items 8-11 as demand-side factors in our analysis.

Starting in week 13 (August 19, 2020), respondents were asked, "How likely are you to apply for Social Security benefits (Retirement, Disability, or Survivors), Supplemental Security Income (SSI) benefits, or Medicare benefits in the next 12 months?" The available choices included: extremely likely, very likely, somewhat likely, or not at all likely. Those who answered extremely, very or somewhat likely were then asked, "How has the coronavirus pandemic affected your decision about applying or not applying for Social Security benefits (Retirement, Disability, or Survivors), Supplemental Security Income (SSI) benefits, or Medicare benefits?" Respondents were provided with four choices:

1. The coronavirus pandemic has not affected my decision about applying for benefits

2. I have decided not to apply

3. I applied or decided to apply earlier than expected

4. I applied or decided to apply later than expected

We also analyze whether the response for this question varies depending on whether someone has applied for unemployment insurance. Specifically, the question asks, "Since March 13, 2020, have you applid for Unemployment Insurance (UI) benefits?" 
Appendix B: Heterogeneity by Demographics 
Table B.1: Changes in Employment Categories Following COVID-19 Pandemic by Sex

A. 50-61-Year-Olds

\begin{tabular}{|c|c|c|c|c|c|c|c|}
\hline & $\begin{array}{c}(1) \\
\text { Employed }\end{array}$ & $\begin{array}{c}(2) \\
\text { Emp-Absent }\end{array}$ & $\begin{array}{c}(3) \\
\text { Unemployed }\end{array}$ & $\begin{array}{c}(4) \\
\text { NILF }\end{array}$ & $\begin{array}{c}(5) \\
\text { Retired }\end{array}$ & $\begin{array}{c}(6) \\
\text { Disabled }\end{array}$ & $\begin{array}{c}(7) \\
\text { Other }\end{array}$ \\
\hline Post-Covid & $\begin{array}{c}-0.0572^{* * *} \\
(0.00404)\end{array}$ & $\begin{array}{c}0.00618^{* * *} \\
(0.00118)\end{array}$ & $\begin{array}{l}0.0337^{* * *} \\
(0.00288)\end{array}$ & $\begin{array}{l}0.0174^{* * *} \\
(0.00299)\end{array}$ & $\begin{array}{l}0.00392^{*} \\
(0.00198)\end{array}$ & $\begin{array}{l}-0.00365 \\
(0.00220)\end{array}$ & $\begin{array}{l}0.0171^{* * *} \\
(0.00179)\end{array}$ \\
\hline Post-Covid x Female & $\begin{array}{l}0.000159 \\
(0.00443)\end{array}$ & $\begin{array}{l}-0.00146 \\
(0.00135)\end{array}$ & $\begin{array}{l}0.00401^{* *} \\
(0.00171)\end{array}$ & $\begin{array}{l}-0.00271 \\
(0.00419)\end{array}$ & $\begin{array}{l}-0.00117 \\
(0.00248)\end{array}$ & $\begin{array}{l}-0.00188 \\
(0.00305)\end{array}$ & $\begin{array}{l}0.000334 \\
(0.00213)\end{array}$ \\
\hline Observations & 1505301 & 1505301 & 1505301 & 1505301 & 1505301 & 1505301 & 1505301 \\
\hline Pre-Covid Mean - Males & 0.747 & 0.0249 & 0.0261 & 0.202 & 0.0646 & 0.101 & 0.0365 \\
\hline Pre-Covid Mean - Females & 0.632 & 0.0277 & 0.0213 & 0.319 & 0.0943 & 0.108 & 0.117 \\
\hline \multicolumn{8}{|c|}{ B. 62-70-Year-Olds } \\
\hline & $\begin{array}{c}(1) \\
\text { Employed }\end{array}$ & $\begin{array}{c}(2) \\
\text { Emp-Absent }\end{array}$ & $\begin{array}{c}(3) \\
\text { Unemployed }\end{array}$ & $\begin{array}{c}(4) \\
\text { NILF }\end{array}$ & $\begin{array}{c}(5) \\
\text { Retired }\end{array}$ & $\begin{array}{c}(6) \\
\text { Disabled }\end{array}$ & $\begin{array}{c}(7) \\
\text { Other }\end{array}$ \\
\hline Post-Covid & $\begin{array}{c}-0.0334^{* * *} \\
(0.00396)\end{array}$ & $\begin{array}{l}0.00363^{* * *} \\
(0.000942)\end{array}$ & $\begin{array}{l}0.0200^{* * *} \\
(0.00197)\end{array}$ & $\begin{array}{c}0.00984^{* * *} \\
(0.00346)\end{array}$ & $\begin{array}{l}0.00903^{* *} \\
(0.00438)\end{array}$ & $\begin{array}{c}-0.00693^{* *} \\
(0.00277)\end{array}$ & $\begin{array}{c}0.00773^{* * *} \\
(0.00130)\end{array}$ \\
\hline Post-Covid x Female & $\begin{array}{c}-0.0100^{* * *} \\
(0.00307) \\
\end{array}$ & $\begin{array}{c}-0.00101 \\
(0.000944) \\
\end{array}$ & $\begin{array}{l}-0.00145 \\
(0.00158) \\
\end{array}$ & $\begin{array}{l}0.0125^{* * *} \\
(0.00357) \\
\end{array}$ & $\begin{array}{c}0.00513 \\
(0.00407) \\
\end{array}$ & $\begin{array}{l}0.00525^{* *} \\
(0.00255) \\
\end{array}$ & $\begin{array}{c}0.00209 \\
(0.00164) \\
\end{array}$ \\
\hline Observations & 999143 & 999143 & 999143 & 999143 & 999143 & 999143 & 999143 \\
\hline Pre-Covid Mean - Males & 0.412 & 0.0197 & 0.0146 & 0.554 & 0.452 & 0.0793 & 0.0224 \\
\hline Pre-Covid Mean - Females & 0.319 & 0.0179 & 0.0108 & 0.653 & 0.526 & 0.0785 & 0.0480 \\
\hline
\end{tabular}

Standard errors in parentheses

${ }^{*} p<0.10,{ }^{* *} p<0.05,{ }^{* * *} p<0.01$

Notes: Samples contain civilians ages 50-61 and 62-70 from the January 2015-March 2021 CPS living in the United States. Outcome variable is whether or not an individual is employed, unemployed, or not in the labor force (NILF) due to any reason; NILF is also subdivided into reasons of disability, retirement, or another reason. An individual is classified as employed-absent if they are absent from their job for a temporary reason during the survey reference week. Standard errors are robust and clustered at the state level. Standard errors are robust and clustered at the state level. Estimates are weighted using survey weights. The Post-Covid estimate captures the change in employment outcome using January 2015-February 2020 as the pre-period and March 2020-March 2021 as the post-period. Regressions include a time trend, and month and state fixed effects, and adjust for age, sex, race, Hispanic ethnicity, education, and household family size. Pre-Covid means captures the mean of the dependent variable in the pre-period January 2015-February 2020. 
Table B.2: Changes in Employment Categories Following COVID-19 Pandemic by Education

A. 50-61-Year-Olds

\begin{tabular}{|c|c|c|c|c|c|c|c|}
\hline & $\begin{array}{c}(1) \\
\text { Employed }\end{array}$ & $\begin{array}{c}(2) \\
\text { Emp-Absent }\end{array}$ & $\begin{array}{c}(3) \\
\text { Unemployed }\end{array}$ & $\begin{array}{c}(4) \\
\text { NILF }\end{array}$ & $\begin{array}{c}(5) \\
\text { Retired }\end{array}$ & $\begin{array}{c}(6) \\
\text { Disabled }\end{array}$ & $\begin{array}{c}(7) \\
\text { Other }\end{array}$ \\
\hline Post-Covid & $\begin{array}{c}-0.0453^{* * *} \\
(0.00420)\end{array}$ & $\begin{array}{r}-0.000227 \\
(0.00107)\end{array}$ & $\begin{array}{l}0.0278^{* * *} \\
(0.00263)\end{array}$ & $\begin{array}{l}0.0177^{* * *} \\
(0.00431)\end{array}$ & $\begin{array}{c}0.00305 \\
(0.00210)\end{array}$ & $\begin{array}{c}0.00290 \\
(0.00203)\end{array}$ & $\begin{array}{l}0.0118^{* * *} \\
(0.00233)\end{array}$ \\
\hline Post-Covid x Low Educ & $\begin{array}{c}-0.0177^{* * *} \\
(0.00506)\end{array}$ & $\begin{array}{l}0.00883^{* * *} \\
(0.000952)\end{array}$ & $\begin{array}{l}0.0123^{* * *} \\
(0.00211)\end{array}$ & $\begin{array}{l}-0.00343 \\
(0.00463)\end{array}$ & $\begin{array}{l}0.000429 \\
(0.00232)\end{array}$ & $\begin{array}{c}-0.0122^{* * *} \\
(0.00208)\end{array}$ & $\begin{array}{c}0.00835^{* * *} \\
(0.00309)\end{array}$ \\
\hline Observations & 1505301 & 1505301 & 1505301 & 1505301 & 1505301 & 1505301 & 1505301 \\
\hline Pre-Covid Mean - High Educ & 0.782 & 0.0322 & 0.0207 & 0.165 & 0.0783 & 0.0300 & 0.0565 \\
\hline Pre-Covid Mean - Low Educ & 0.642 & 0.0235 & 0.0250 & 0.309 & 0.0807 & 0.141 & 0.0879 \\
\hline \multicolumn{8}{|c|}{ B. 62-70-Year-Olds } \\
\hline & $(1)$ & $(2)$ & $(3)$ & $(4)$ & $(5)$ & $(6)$ & $(7)$ \\
\hline & Employed & Emp-Absent & Unemployed & NILF & Retired & Disabled & Other \\
\hline Post-Covid & $\begin{array}{c}-0.0451^{* * *} \\
(0.00585)\end{array}$ & $\begin{array}{r}-0.000618 \\
(0.00142)\end{array}$ & $\begin{array}{l}0.0184^{* * *} \\
(0.00198)\end{array}$ & $\begin{array}{l}0.0273^{* * *} \\
(0.00518)\end{array}$ & $\begin{array}{l}0.0182^{* * *} \\
(0.00503)\end{array}$ & $\begin{array}{c}-0.000574 \\
(0.00232)\end{array}$ & $\begin{array}{c}0.00970^{\text {*** }} \\
(0.00130)\end{array}$ \\
\hline Post-Covid x Low Educ & $\begin{array}{c}0.00993^{*} \\
(0.00535) \\
\end{array}$ & $\begin{array}{c}0.00565^{* * *} \\
(0.00162) \\
\end{array}$ & $\begin{array}{c}0.00121 \\
(0.00183) \\
\end{array}$ & $\begin{array}{c}-0.0168^{* * *} \\
(0.00519) \\
\end{array}$ & $\begin{array}{c}-0.00963^{* *} \\
(0.00466) \\
\end{array}$ & $\begin{array}{c}-0.00578^{* *} \\
(0.00268) \\
\end{array}$ & $\begin{array}{l}-0.00138 \\
(0.00185) \\
\end{array}$ \\
\hline Observations & 999143 & 999143 & 999143 & 999143 & 999143 & 999143 & 999143 \\
\hline Pre-Covid Mean - High Educ & 0.449 & 0.0259 & 0.0141 & 0.511 & 0.458 & 0.0257 & 0.0274 \\
\hline Pre-Covid Mean - Low Educ & 0.320 & 0.0153 & 0.0119 & 0.653 & 0.508 & 0.105 & 0.0402 \\
\hline
\end{tabular}

Standard errors in parentheses

${ }^{*} p<0.10,{ }^{* *} p<0.05,{ }^{* * *} p<0.01$

Notes: Sample contains civilians ages 50-61 and 62-70 from the January 2015-March 2021 CPS living in the United States. Outcome variable is whether or not an individual is employed, unemployed, or not in the labor force (NILF) due to any reason; NILF is also subdivided into reasons of disability, retirement, or another reason. An individual is classified as employed-absent if they are absent from their job for a temporary reason during the survey reference week. Standard errors are robust and clustered at the state level. Standard errors are robust and clustered at the state level. Estimates are weighted using survey weights. The Post-Covid estimate captures the change in employment outcome using January 2015-February 2020 as the pre-period and March 2020-March 2021 as the post-period. Regressions include a time trend, and month and state fixed effects, and adjust for age, sex, race, Hispanic ethnicity, education, and household family size. Pre-Covid means captures the mean of the dependent variable in the pre-period January 2015-February 2020. 
Table B.3: Changes in Employment Categories Following COVID-19 Pandemic by Race/Ethnicity

A. 50-61-Year-Olds

\begin{tabular}{|c|c|c|c|c|c|c|c|}
\hline & $\begin{array}{c}(1) \\
\text { Employed }\end{array}$ & $\begin{array}{c}(2) \\
\text { Emp-Absent }\end{array}$ & $\begin{array}{c}(3) \\
\text { Unemployed }\end{array}$ & $\begin{array}{c}(4) \\
\text { NILF }\end{array}$ & $\begin{array}{c}(5) \\
\text { Retired }\end{array}$ & $\begin{array}{c}(6) \\
\text { Disabled }\end{array}$ & $\begin{array}{c}(7) \\
\text { Other }\end{array}$ \\
\hline Post-Covid & $\begin{array}{c}-0.0521^{* * *} \\
(0.00356)\end{array}$ & $\begin{array}{l}0.00388^{* * *} \\
(0.000896)\end{array}$ & $\begin{array}{l}0.0308^{* * *} \\
(0.00211)\end{array}$ & $\begin{array}{l}0.0174^{* * *} \\
(0.00352)\end{array}$ & $\begin{array}{l}0.00453^{* *} \\
(0.00201)\end{array}$ & $\begin{array}{l}-0.00177 \\
(0.00214)\end{array}$ & $\begin{array}{l}0.0147^{* * *} \\
(0.00180)\end{array}$ \\
\hline Post-Covid x Black & $\begin{array}{l}0.000249 \\
(0.00695)\end{array}$ & $\begin{array}{l}0.00441^{* *} \\
(0.00207)\end{array}$ & $\begin{array}{c}0.00404 \\
(0.00309)\end{array}$ & $\begin{array}{l}-0.00870 \\
(0.00628)\end{array}$ & $\begin{array}{l}-0.00445 \\
(0.00461)\end{array}$ & $\begin{array}{c}-0.0133^{* *} \\
(0.00506)\end{array}$ & $\begin{array}{l}0.00906^{* *} \\
(0.00413)\end{array}$ \\
\hline Post-Covid x Other & $\begin{array}{c}-0.0302^{* * *} \\
(0.00945)\end{array}$ & $\begin{array}{c}0.00142 \\
(0.00192)\end{array}$ & $\begin{array}{l}0.0218^{* * *} \\
(0.00420)\end{array}$ & $\begin{array}{c}0.00700 \\
(0.00713)\end{array}$ & $\begin{array}{l}-0.00541 \\
(0.00523)\end{array}$ & $\begin{array}{c}0.00103 \\
(0.00398)\end{array}$ & $\begin{array}{c}0.0114^{* *} \\
(0.00511)\end{array}$ \\
\hline Post-Covid x Hispanic & $\begin{array}{c}-0.0166^{* * *} \\
(0.00556)\end{array}$ & $\begin{array}{l}0.00601^{* *} \\
(0.00227)\end{array}$ & $\begin{array}{l}0.0172^{* * *} \\
(0.00266)\end{array}$ & $\begin{array}{l}-0.00658 \\
(0.00578)\end{array}$ & $\begin{array}{l}-0.00132 \\
(0.00289)\end{array}$ & $\begin{array}{l}-0.00869^{*} \\
(0.00519)\end{array}$ & $\begin{array}{c}0.00343 \\
(0.00454)\end{array}$ \\
\hline Observations & 1505301 & 1505301 & 1505301 & 1505301 & 1505301 & 1505301 & 1505301 \\
\hline Pre-Covid Mean - White & 0.700 & 0.0272 & 0.0224 & 0.251 & 0.0806 & 0.0955 & 0.0744 \\
\hline Pre-Covid Mean - Black & 0.612 & 0.0216 & 0.0319 & 0.334 & 0.0772 & 0.182 & 0.0756 \\
\hline Pre-Covid Mean - Other & 0.681 & 0.0248 & 0.0232 & 0.271 & 0.0768 & 0.0810 & 0.114 \\
\hline Pre-Covid Mean - Hispanic & 0.671 & 0.0232 & 0.0286 & 0.277 & 0.0572 & 0.0925 & 0.127 \\
\hline
\end{tabular}

Standard errors in parentheses

${ }^{*} p<0.10,{ }^{* *} p<0.05,{ }^{* * *} p<0.01$

Notes: Table continued on next page. 
Table B.3: Changes in Employment Categories Following COVID-19 Pandemic by Race/Ethnicity (cont.)

B. 62-70-Year-Olds

\begin{tabular}{|c|c|c|c|c|c|c|c|}
\hline & $\begin{array}{c}(1) \\
\text { Employed }\end{array}$ & $\begin{array}{c}(2) \\
\text { Emp-Absent }\end{array}$ & $\begin{array}{c}(3) \\
\text { Unemployed }\end{array}$ & $\begin{array}{c}(4) \\
\text { NILF }\end{array}$ & $\begin{array}{c}(5) \\
\text { Retired }\end{array}$ & $\begin{array}{c}(6) \\
\text { Disabled }\end{array}$ & $\begin{array}{c}(7) \\
\text { Other }\end{array}$ \\
\hline Post-Covid & $\begin{array}{c}-0.0370^{* * *} \\
(0.00422)\end{array}$ & $\begin{array}{l}0.00264^{* * *} \\
(0.000849)\end{array}$ & $\begin{array}{l}0.0172^{* * *} \\
(0.00168)\end{array}$ & $\begin{array}{l}0.0172^{* * *} \\
(0.00375)\end{array}$ & $\begin{array}{l}0.0157^{* * *} \\
(0.00370)\end{array}$ & $\begin{array}{c}-0.00544^{* *} \\
(0.00236)\end{array}$ & $\begin{array}{c}0.00694^{* * *} \\
(0.00135)\end{array}$ \\
\hline Post-Covid x Black & $\begin{array}{r}-0.00548 \\
(0.0108)\end{array}$ & $\begin{array}{l}0.000599 \\
(0.00161)\end{array}$ & $\begin{array}{c}0.00160 \\
(0.00251)\end{array}$ & $\begin{array}{l}0.00328 \\
(0.0101)\end{array}$ & $\begin{array}{l}-0.00486 \\
(0.00859)\end{array}$ & $\begin{array}{c}0.00398 \\
(0.00689)\end{array}$ & $\begin{array}{c}0.00417 \\
(0.00360)\end{array}$ \\
\hline Post-Covid x Other & $\begin{array}{c}-0.0224^{* *} \\
(0.0111)\end{array}$ & $\begin{array}{c}0.00301 \\
(0.00276)\end{array}$ & $\begin{array}{l}0.0152^{* * *} \\
(0.00352)\end{array}$ & $\begin{array}{l}0.00413 \\
(0.0120)\end{array}$ & $\begin{array}{l}-0.0177 \\
(0.0142)\end{array}$ & $\begin{array}{c}0.00894 \\
(0.00676)\end{array}$ & $\begin{array}{l}0.0129^{* * *} \\
(0.00430)\end{array}$ \\
\hline Post-Covid x Hispanic & $\begin{array}{c}0.00557 \\
(0.00782)\end{array}$ & $\begin{array}{c}0.00167 \\
(0.00164)\end{array}$ & $\begin{array}{l}0.00725^{* *} \\
(0.00295)\end{array}$ & $\begin{array}{l}-0.0145^{*} \\
(0.00810)\end{array}$ & $\begin{array}{l}-0.0211^{* *} \\
(0.00846)\end{array}$ & $\begin{array}{c}0.00179 \\
(0.00826)\end{array}$ & $\begin{array}{c}0.00481 \\
(0.00425)\end{array}$ \\
\hline Observations & 999143 & 999143 & 999143 & 999143 & 999143 & 999143 & 999143 \\
\hline Pre-Covid Mean - White & 0.369 & 0.0197 & 0.0118 & 0.599 & 0.497 & 0.0692 & 0.0327 \\
\hline Pre-Covid Mean - Black & 0.310 & 0.0133 & 0.0172 & 0.659 & 0.458 & 0.155 & 0.0455 \\
\hline Pre-Covid Mean - Other & 0.366 & 0.0164 & 0.0154 & 0.602 & 0.470 & 0.0736 & 0.0593 \\
\hline Pre-Covid Mean - Hispanic & 0.343 & 0.0142 & 0.0163 & 0.627 & 0.451 & 0.103 & 0.0731 \\
\hline
\end{tabular}

Standard errors in parentheses

${ }^{*} p<0.10,{ }^{* *} p<0.05,{ }^{* * *} p<0.01$

Notes: Sample contains civilians ages 50-61 and 62-70 from the January 2015-March 2021 CPS living in the United States. Outcome variable is whether or not an individual is employed, unemployed, or not in the labor force (NILF) due to any reason; NILF is also subdivided into reasons of disability, retirement, or another reason. An individual is classified as employed-absent if they are absent from their job for a temporary reason during the survey reference week. Standard errors are robust and clustered at the state level. Standard errors are robust and clustered at the state level. Estimates are weighted using survey weights. The Post-Covid estimate captures the change in employment outcome using January 2015-February 2020 as the pre-period and March 2020-March 2021 as the post-period. Regressions include a time trend, and month and state fixed effects, and adjust for age, sex, race, Hispanic ethnicity, education, and household family size. Pre-Covid means captures the mean of the dependent variable in the pre-period January 2015-February 2020. 
Table B.4: Changes in Employment Categories Following COVID-19 Pandemic by Living Arrangements

A. 50-61-Year-Olds

\begin{tabular}{lccccccc}
\hline \hline & $(1)$ & $(2)$ & $(3)$ & $(4)$ & $(5)$ & $(6)$ & $(7)$ \\
& Employed & Emp-Absent & Unemployed & NILF & Retired & Disabled & Other \\
\hline Post-Covid & $-0.0569^{* * *}$ & $0.00483^{* * *}$ & $0.0356^{* * *}$ & $0.0165^{* * *}$ & 0.00208 & -0.00177 & $0.0162^{* * *}$ \\
& $(0.00351)$ & $(0.000825)$ & $(0.00273)$ & $(0.00279)$ & $(0.00157)$ & $(0.00184)$ & $(0.00165)$ \\
Post-Covid x Lives Alone & & & & & & & \\
& -0.00303 & $0.00345^{* * *}$ & 0.00124 & -0.00166 & $0.00680^{* *}$ & $-0.0135^{* * *}$ & $0.00505^{* *}$ \\
& $(0.00617)$ & $(0.00128)$ & $(0.00216)$ & $(0.00518)$ & $(0.00328)$ & $(0.00399)$ & $(0.00238)$ \\
\hline Obersvations & 1505301 & 1505301 & 1505301 & 1505301 & 1505301 & 1505301 & 1505301 \\
Pre-Covid Mean - Lives with Others & 0.700 & 0.0269 & 0.0220 & 0.251 & 0.0808 & 0.0861 & 0.0838 \\
Pre-Covid Mean - Lives Alone & 0.629 & 0.0240 & 0.0310 & 0.316 & 0.0756 & 0.191 & 0.0497 \\
\hline \hline
\end{tabular}

B. 62-70-Year-Olds

\begin{tabular}{|c|c|c|c|c|c|c|c|}
\hline & $\begin{array}{c}(1) \\
\text { Employed }\end{array}$ & $\begin{array}{c}(2) \\
\text { Emp-Absent }\end{array}$ & $\begin{array}{c}(3) \\
\text { Unemployed }\end{array}$ & $\begin{array}{c}(4) \\
\text { NILF }\end{array}$ & $\begin{array}{c}(5) \\
\text { Retired }\end{array}$ & $\begin{array}{c}(6) \\
\text { Disabled }\end{array}$ & $\begin{array}{c}\text { (7) } \\
\text { Other }\end{array}$ \\
\hline Post-Covid & $\begin{array}{c}-0.0352^{* * *} \\
(0.00391)\end{array}$ & $\begin{array}{l}0.00284^{* * *} \\
(0.000858)\end{array}$ & $\begin{array}{l}0.0190^{* * *} \\
(0.00159)\end{array}$ & $\begin{array}{l}0.0134^{* * *} \\
(0.00343)\end{array}$ & $\begin{array}{l}0.00774^{* *} \\
(0.00358)\end{array}$ & $\begin{array}{l}-0.00337 \\
(0.00221)\end{array}$ & $\begin{array}{c}0.00901^{* * *} \\
(0.00135)\end{array}$ \\
\hline Post-Covid x Lives Alone & $\begin{array}{c}-0.0151^{* * *} \\
(0.00537)\end{array}$ & $\begin{array}{c}0.00110 \\
(0.00158)\end{array}$ & $\begin{array}{l}0.000768 \\
(0.00249)\end{array}$ & $\begin{array}{c}0.0132^{* *} \\
(0.00597)\end{array}$ & $\begin{array}{c}0.0172^{* *} \\
(0.00761)\end{array}$ & $\begin{array}{l}-0.00317 \\
(0.00339)\end{array}$ & $\begin{array}{r}-0.000789 \\
(0.00284)\end{array}$ \\
\hline Obersvations & 999143 & 999143 & 999143 & 999143 & 999143 & 999143 & 999143 \\
\hline Pre-Covid Mean - Lives with Others & 0.370 & 0.0194 & 0.0110 & 0.599 & 0.500 & 0.0626 & 0.0368 \\
\hline Pre-Covid Mean - Lives Alone & 0.337 & 0.0168 & 0.0179 & 0.628 & 0.462 & 0.133 & 0.0330 \\
\hline
\end{tabular}

Standard errors in parentheses

${ }^{*} p<0.10,{ }^{* *} p<0.05,{ }^{* * *} p<0.01$

Notes: Sample contains civilians ages 50-61 and 62-70 from the January 2015-March 2021 CPS living in the United States. Outcome variable is whether or not an individual is employed, unemployed, or not in the labor force (NILF) due to any reason; NILF is also subdivided into reasons of disability, retirement, or another reason. An individual is classified as employed-absent if they are absent from their job for a temporary reason during the survey reference week. Standard errors are robust and clustered at the state level. Standard errors are robust and clustered at the state level. Estimates are weighted using survey weights. The Post-Covid estimate captures the change in employment outcome using January 2015-February 2020 as the pre-period and March 2020-March 2021 as the post-period. Regressions include a time trend, and month and state fixed effects, and adjust for age, sex, race, Hispanic ethnicity, education, and household family size. Pre-Covid means captures the mean of the dependent variable in the pre-period January 2015-February 2020. 


\section{Appendix C: Heterogeneity by Area \\ C.1 Current Population Survey}


Table C.1: Changes in Employment Categories Following COVID-19 Pandemic by COVID-Induced Labor Demand Shock

A. 50-61-Year-Olds

\begin{tabular}{|c|c|c|c|c|c|c|c|}
\hline & $\begin{array}{c}\text { (1) } \\
\text { Employed }\end{array}$ & $\begin{array}{c}(2) \\
\text { Emp-Absent }\end{array}$ & $\begin{array}{c}(3) \\
\text { Unemployed }\end{array}$ & $\begin{array}{c}(4) \\
\text { NILF }\end{array}$ & $\begin{array}{c}(5) \\
\text { Retired }\end{array}$ & $\begin{array}{c}(6) \\
\text { Disabled }\end{array}$ & $\begin{array}{c}(7) \\
\text { Other }\end{array}$ \\
\hline Post-Covid & $\begin{array}{c}-0.0539^{* * *} \\
(0.00419)\end{array}$ & $\begin{array}{c}0.00498^{* * *} \\
(0.00103)\end{array}$ & $\begin{array}{l}0.0331^{* * *} \\
(0.00275)\end{array}$ & $\begin{array}{l}0.0158^{* * *} \\
(0.00361)\end{array}$ & $\begin{array}{l}0.00451^{* *} \\
(0.00186)\end{array}$ & $\begin{array}{c}-0.00561^{* *} \\
(0.00224)\end{array}$ & $\begin{array}{l}0.0169^{* * *} \\
(0.00254)\end{array}$ \\
\hline Post-Covid x High Covid Shock & $\begin{array}{l}-0.00629 \\
(0.00553)\end{array}$ & $\begin{array}{l}0.000938 \\
(0.00131)\end{array}$ & $\begin{array}{c}0.00511^{*} \\
(0.00279)\end{array}$ & $\begin{array}{l}0.000239 \\
(0.00476)\end{array}$ & $\begin{array}{l}-0.00223 \\
(0.00227)\end{array}$ & $\begin{array}{c}0.00183 \\
(0.00273)\end{array}$ & $\begin{array}{l}0.000637 \\
(0.00315)\end{array}$ \\
\hline Observations & 1501262 & 1501262 & 1501262 & 1501262 & 1501262 & 1501262 & 1501262 \\
\hline Pre-Covid Mean - High Covid Shock & 0.686 & 0.0259 & 0.0239 & 0.264 & 0.0817 & 0.101 & 0.0814 \\
\hline Pre-Covid Mean - Low Covid Shock & 0.689 & 0.0268 & 0.0233 & 0.261 & 0.0780 & 0.109 & 0.0736 \\
\hline
\end{tabular}

B. 62-70-Year-Olds

\begin{tabular}{|c|c|c|c|c|c|c|c|}
\hline & $\begin{array}{c}(1) \\
\text { Employed }\end{array}$ & $\begin{array}{c}(2) \\
\text { Emp-Absent }\end{array}$ & $\begin{array}{c}(3) \\
\text { Unemployed }\end{array}$ & $\begin{array}{c}(4) \\
\text { NILF }\end{array}$ & $\begin{array}{c}(5) \\
\text { Retired }\end{array}$ & $\begin{array}{c}(6) \\
\text { Disabled }\end{array}$ & $\begin{array}{c}(7) \\
\text { Other }\end{array}$ \\
\hline Post-Covid & $\begin{array}{c}-0.0312^{* * *} \\
(0.00442)\end{array}$ & $\begin{array}{c}0.00386^{* * *} \\
(0.00106)\end{array}$ & $\begin{array}{l}0.0161^{* * *} \\
(0.00193)\end{array}$ & $\begin{array}{l}0.0112^{* * *} \\
(0.00417)\end{array}$ & $\begin{array}{c}0.00850 \\
(0.00537)\end{array}$ & $\begin{array}{c}-0.00617^{* *} \\
(0.00301)\end{array}$ & $\begin{array}{c}0.00888^{* * *} \\
(0.00175)\end{array}$ \\
\hline Post-Covid x High Covid Shock & $\begin{array}{l}-0.0141^{* *} \\
(0.00617)\end{array}$ & $\begin{array}{l}-0.00148 \\
(0.00122)\end{array}$ & $\begin{array}{c}0.00591^{* *} \\
(0.00243)\end{array}$ & $\begin{array}{c}0.00968 \\
(0.00698)\end{array}$ & $\begin{array}{c}0.00605 \\
(0.00839)\end{array}$ & $\begin{array}{c}0.00365 \\
(0.00366)\end{array}$ & $\begin{array}{c}-0.0000210 \\
(0.00233)\end{array}$ \\
\hline Observations & 996806 & 996806 & 996806 & 996806 & 996806 & 996806 & 996806 \\
\hline Pre-Covid Mean- High Covid Shock & 0.361 & 0.0183 & 0.0128 & 0.608 & 0.494 & 0.0761 & 0.0379 \\
\hline Pre-Covid Mean - Low Covid Shock & 0.365 & 0.0193 & 0.0124 & 0.604 & 0.488 & 0.0818 & 0.0337 \\
\hline
\end{tabular}

Standard errors in parentheses

${ }^{*} p<0.10,{ }^{* *} p<0.05,{ }^{* * *} p<0.01$

Notes: Sample contains civilians ages 50-61 and 62-70 from the January 2015-March 2021 CPS living in the United States. Outcome variable is whether or not an individual is employed, unemployed, or not in the labor force (NILF) due to any reason; NILF is also subdivided into reasons of disability, retirement, or another reason. An individual is classified as employed-absent if they are absent from their job for a temporary reason during the survey reference week. A High Covid Shock is a binary variable indicating whether or not an individual belongs to a county where the share of non-essential and non-teleworkable is greater than or equal to the median share across the country. Standard errors are robust and clustered at the state level. Standard errors are robust and clustered at the state level. Estimates are weighted using survey weights. The Post-Covid estimate captures the change in employment outcome using January 2015-February 2020 as the pre-period and March 2020-March 2021 as the post-period. Regressions include a time trend, and month and state fixed effects, and adjust for age, sex, race, Hispanic ethnicity, education, and household family size. Pre-Covid means captures the mean of the dependent variable in the pre-period January 2015-February 2020. 
Table C.2: Changes in Employment Categories Following COVID-19 Pandemic by COVID-Induced Shutdown

A. 50-61-Year-Olds

\begin{tabular}{|c|c|c|c|c|c|c|c|}
\hline & $\begin{array}{c}(1) \\
\text { Employed }\end{array}$ & $\begin{array}{c}(2) \\
\text { Emp-Absent }\end{array}$ & $\begin{array}{c}(3) \\
\text { Unemployed }\end{array}$ & $\begin{array}{c}(4) \\
\text { NILF }\end{array}$ & $\begin{array}{c}(5) \\
\text { Retired }\end{array}$ & $\begin{array}{c}(6) \\
\text { Disabled }\end{array}$ & $\begin{array}{c}(7) \\
\text { Other }\end{array}$ \\
\hline Post-Covid & $\begin{array}{c}-0.0471^{* * *} \\
(0.00519)\end{array}$ & $\begin{array}{l}0.00433^{* * *} \\
(0.000943)\end{array}$ & $\begin{array}{l}0.0288^{* * *} \\
(0.00182)\end{array}$ & $\begin{array}{l}0.0139^{* * *} \\
(0.00432)\end{array}$ & $\begin{array}{c}0.00547^{* * *} \\
(0.00159)\end{array}$ & $\begin{array}{l}-0.00539^{*} \\
(0.00281)\end{array}$ & $\begin{array}{l}0.0139^{* * *} \\
(0.00230)\end{array}$ \\
\hline Post-Covid x Shutdown & $\begin{array}{c}-0.0164^{* * *} \\
(0.00587)\end{array}$ & $\begin{array}{c}0.00180 \\
(0.00111)\end{array}$ & $\begin{array}{l}0.0112^{* * *} \\
(0.00337)\end{array}$ & $\begin{array}{c}0.00334 \\
(0.00448)\end{array}$ & $\begin{array}{l}-0.00351 \\
(0.00255)\end{array}$ & $\begin{array}{c}0.00126 \\
(0.00221)\end{array}$ & $\begin{array}{l}0.00559^{* *} \\
(0.00259)\end{array}$ \\
\hline Observations & 1505301 & 1505301 & 1505301 & 1505301 & 1505301 & 1505301 & 1505301 \\
\hline Pre-Covid Mean - More Shutdown & 0.691 & 0.0274 & 0.0251 & 0.256 & 0.0795 & 0.0981 & 0.0786 \\
\hline Pre-Covid Mean - Less Shutdown & 0.682 & 0.0246 & 0.0213 & 0.272 & 0.0806 & 0.116 & 0.0761 \\
\hline
\end{tabular}

B. 62-70-Year-Olds

\begin{tabular}{|c|c|c|c|c|c|c|c|}
\hline & $\begin{array}{c}(1) \\
\text { Employed }\end{array}$ & $\begin{array}{c}(2) \\
\text { Emp-Absent }\end{array}$ & $\begin{array}{c}(3) \\
\text { Unemployed }\end{array}$ & $\begin{array}{c}\text { (4) } \\
\text { NILF }\end{array}$ & $\begin{array}{c}5) \\
\text { Retired }\end{array}$ & $\begin{array}{c}(6) \\
\text { Disabled }\end{array}$ & $\begin{array}{c}\text { (7) } \\
\text { Other }\end{array}$ \\
\hline Post-Covid & $\begin{array}{c}-0.0319^{* * *} \\
(0.00609)\end{array}$ & $\begin{array}{c}0.00284^{* * *} \\
(0.00104)\end{array}$ & $\begin{array}{l}0.0134^{* * *} \\
(0.00140)\end{array}$ & $\begin{array}{l}0.0157^{* * *} \\
(0.00534)\end{array}$ & $\begin{array}{c}0.0122^{* *} \\
(0.00540)\end{array}$ & $\begin{array}{l}-0.00266 \\
(0.00312)\end{array}$ & $\begin{array}{c}0.00617^{* * *} \\
(0.00156)\end{array}$ \\
\hline Post-Covid x Shutdown & $\begin{array}{c}-0.0111 \\
(0.00669)\end{array}$ & $\begin{array}{l}0.000413 \\
(0.00126)\end{array}$ & $\begin{array}{c}0.00956^{* * *} \\
(0.00218)\end{array}$ & $\begin{array}{c}0.00114 \\
(0.00539)\end{array}$ & $\begin{array}{l}-0.000777 \\
(0.00502)\end{array}$ & $\begin{array}{l}-0.00245 \\
(0.00276)\end{array}$ & $\begin{array}{l}0.00437^{*} \\
(0.00224)\end{array}$ \\
\hline Observations & 999143 & 999143 & 999143 & 999143 & 999143 & 999143 & 999143 \\
\hline Pre-Covid Mean - More Shutdown & 0.370 & 0.0199 & 0.0139 & 0.596 & 0.486 & 0.0735 & 0.0369 \\
\hline Pre-Covid Mean - Less Shutdown & 0.351 & 0.0171 & 0.0106 & 0.621 & 0.499 & 0.0874 & 0.0344 \\
\hline
\end{tabular}

Standard errors in parentheses

${ }^{*} p<0.10,{ }^{* *} p<0.05,{ }^{* * *} p<0.01$

Notes:Sample contains civilians ages 50-61 and 62-70 from the January 2015-March 2021 CPS living in the United States. Outcome variable is whether or not an individual is employed, unemployed, or not in the labor force (NILF) due to any reason; NILF is also subdivided into reasons of disability, retirement, or another reason. An individual is classified as employed-absent if they are absent from their job for a temporary reason during the survey reference week. Shutdown is a binary variable indicating whether or not an individual belongs to a state above or equal to median openness as defined in the Baker Institute report. Standard errors are robust and clustered at the state level. Standard errors are robust and clustered at the state level. Estimates are weighted using survey weights. The Post-Covid estimate captures the change in employment outcome using January 2015-February 2020 as the pre-period and March 2020-March 2021 as the post-period. Regressions include a time trend, and month and state fixed effects, and adjust for age, sex, race, Hispanic ethnicity, education, and household family size. Pre-Covid means captures the mean of the dependent variable in the pre-period January 2015-February 2020. 


\section{C.2 SSDI/SSI Applications}

Table C.3: Changes in Disability Applications Following COVID-19 Pandemic by COVIDInduced Shutdown

\begin{tabular}{lcccc}
\hline \hline & $(1)$ & $(2)$ & $(3)$ & $(4)$ \\
& All & SSDI & SSI & Concurrent \\
\hline Post-Covid & $-3.793^{* * *}$ & $-0.539^{* *}$ & $-2.122^{* * *}$ & $-1.134^{* * *}$ \\
& $(0.745)$ & $(0.259)$ & $(0.329)$ & $(0.230)$ \\
Post-Covid x Shutdown & -0.00770 & -0.133 & 0.0770 & 0.0499 \\
& $(0.925)$ & $(0.354)$ & $(0.372)$ & $(0.278)$ \\
\hline$N$ & 3825 & 3825 & 3825 & 3825 \\
Pre-Covid Mean & 25.39 & 9.54 & 9.46 & 6.39 \\
Pre-Covid Mean x Shutdown & 23.95 & 9.17 & 9.02 & 5.76 \\
Pre-Covid Mean x More Open & 26.90 & 9.94 & 9.91 & 7.05 \\
\hline \hline
\end{tabular}

Robust and clustered (at state level) standard errors in parentheses

${ }^{*} p<0.10,{ }^{* *} p<0.05,{ }^{* * *} p<0.01$

Notes: Sample comes from the SSA State Agency Monthly Workload and ranges from January 2015 to March 2021. Outcome variables represent weekly applications per 100,000 people aged 20 to 64 . Other regressors (not shown) include month, year, and state fixed effects. Post-Covid refers to months March 2020 and later. Shutdown equals 1 if shutdown index is less than or equal to its median. 
Table C.4: Changes in Disability Applications Following COVID-19 Pandemic by COVIDInduced Labor Demand Shock

\begin{tabular}{lcccc}
\hline \hline & $(1)$ & $(2)$ & $(3)$ & $(4)$ \\
& All & SSDI & SSI & Concurrent \\
\hline Post-Covid & $-3.788^{* * *}$ & $-0.680^{* *}$ & $-2.014^{* * *}$ & $-1.096^{* * *}$ \\
& $(0.844)$ & $(0.335)$ & $(0.333)$ & $(0.249)$ \\
Post-Covid x High Covid Shock & -0.0173 & 0.150 & -0.140 & -0.0252 \\
& $(0.912)$ & $(0.350)$ & $(0.367)$ & $(0.275)$ \\
\hline$N$ & 3825 & 3825 & 3825 & 3825 \\
Pre-Covid Mean & 25.39 & 9.54 & 9.46 & 6.39 \\
Pre-Covid Mean x High Covid Shock & 24.84 & 9.56 & 9.19 & 6.08 \\
Pre-Covid Mean x Low Covid Shock & 25.93 & 9.52 & 9.71 & 6.69 \\
\hline \hline
\end{tabular}

Robust and clustered (at state level) standard errors in parentheses

${ }^{*} p<0.10,{ }^{* *} p<0.05,{ }^{* * *} p<0.01$

Notes: Sample comes from the SSA State Agency Monthly Workload and ranges from January 2015 to March 2021. Outcome variables represent weekly applications per 100,000 people aged 20 to 64 . Other regressors (not shown) include month, year, and state fixed effects. Post-Covid refers to months March 2020 and later. High Covid Shock equals 1 if the share of non-essential and non-teleworkable is greater than or equal to its median. 
Table C.5: Changes in Disability Applications Following COVID-19 Pandemic by Internet Access

\begin{tabular}{lcccc}
\hline \hline & $(1)$ & $(2)$ & $(3)$ & $(4)$ \\
& All & SSDI & SSI & Concurrent \\
\hline Post-Covid & $-3.973^{* * *}$ & $-0.510^{* *}$ & $-2.226^{* * *}$ & $-1.238^{* * *}$ \\
& $(0.759)$ & $(0.250)$ & $(0.348)$ & $(0.232)$ \\
Post-Covid x High Connectivity & 0.334 & -0.182 & 0.270 & 0.244 \\
& $(0.931)$ & $(0.352)$ & $(0.380)$ & $(0.278)$ \\
\hline$N$ & 3825 & 3825 & 3825 & 3825 \\
Pre-Covid Mean & 25.39 & 9.54 & 9.46 & 6.39 \\
Pre-Covid Mean x High Connectivity & 21.50 & 8.30 & 7.96 & 5.23 \\
Pre-Covid Mean x Low Connectivity & 29.78 & 10.94 & 11.14 & 7.70 \\
\hline \hline
\end{tabular}

Robust and clustered (at state level) standard errors in parentheses

${ }^{*} p<0.10,{ }^{* *} p<0.05,{ }^{* * *} p<0.01$

Notes: Sample comes from the SSA State Agency Monthly Workload and ranges from January 2015 to March 2021. Outcome variables represent weekly applications per 100,000 people aged 20 to 64. Other regressors (not shown) include month, year, and state fixed effects. Post-Covid refers to months March 2020 and later. High Connectivity equals 1 if the percentage of households with a broadband internet subscription is greater than or equal to its median. 


\section{C.3 Google Trends}

Table C.6: Changes in Google Search Intensity Following COVID-19 Pandemic by COVIDInduced Shutdown

\begin{tabular}{lccc}
\hline \hline & $(1)$ & $(2)$ & $(3)$ \\
& Disability & Retirement & Social Security \\
\hline Post-Covid & $-0.0364^{*}$ & $-0.0738^{* * *}$ & 0.0152 \\
& $(0.019)$ & $(0.014)$ & $(0.013)$ \\
Post-Covid x Shutdown & $-0.0709^{* * *}$ & $-0.0348^{* *}$ & $-0.0379^{* *}$ \\
& $(0.023)$ & $(0.017)$ & $(0.016)$ \\
\hline$N$ & 3825 & 3825 & 3825 \\
Pre-Covid Mean & 4.208 & 4.002 & 4.206 \\
Pre-Covid Mean x Shutdown & 4.130 & 4.039 & 4.117 \\
Pre-Covid Mean x More Open & 4.289 & 3.964 & 4.298 \\
\hline \hline
\end{tabular}

Robust and clustered (at state level) standard errors in parentheses

${ }^{*} p<0.10,{ }^{* *} p<0.05,{ }^{* * *} p<0.01$

Notes: Sample contains search data from January 2015 to March 2021. Outcome variable is the logarithm of search intensity. Other regressors (not shown) include a time trend, and month and state fixed effects. Post-Covid refers to months March 2020 and later. Shutdown equals 1 if shutdown index is less than or equal to its median. 
Table C.7: Changes in Google Search Intensity Following COVID-19 Pandemic by COVIDInduced Labor Demand Shock

\begin{tabular}{lccc}
\hline \hline & $(1)$ & $(2)$ & $(3)$ \\
& Disability & Retirement & Social Security \\
\hline Post-Covid & $-0.0383^{* *}$ & $-0.0938^{* * *}$ & 0.0102 \\
& $(0.019)$ & $(0.015)$ & $(0.013)$ \\
Post-Covid x High Covid Shock & $-0.0697^{* * *}$ & 0.00450 & $-0.0292^{*}$ \\
& $(0.023)$ & $(0.018)$ & $(0.017)$ \\
\hline$N$ & 3825 & 3825 & 3825 \\
Pre-Covid Mean & 4.208 & 4.002 & 4.206 \\
Pre-Covid Mean x High Covid Shock & 4.192 & 3.926 & 4.199 \\
Pre-Covid Mean x Low Covid Shock & 4.222 & 4.076 & 4.213 \\
\hline \hline
\end{tabular}

Robust and clustered (at state level) standard errors in parentheses

${ }^{*} p<0.10,{ }^{* *} p<0.05,{ }^{* * *} p<0.01$

Notes: Sample contains search data from January 2015 to March 2021. Outcome variable is the logarithm of search intensity. Other regressors (not shown) include a time trend, and month and state fixed effects. Post-Covid refers to months March 2020 and later. High Covid Shock equals 1 if the share of non-essential and non-teleworkable is greater than or equal to its median. 


\section{Appendix D: Census Household Pulse Survey Analysis}

Figure D.1: Reasons for Not Working

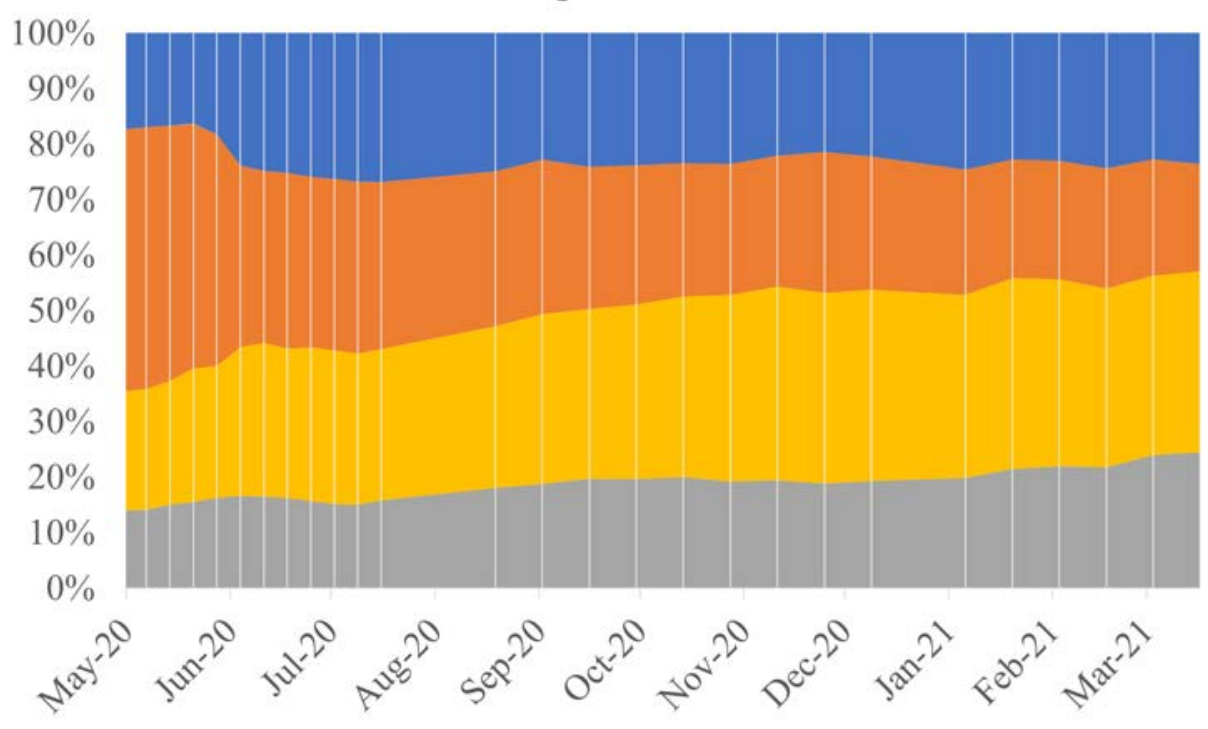

(a) 50-61 Year Olds

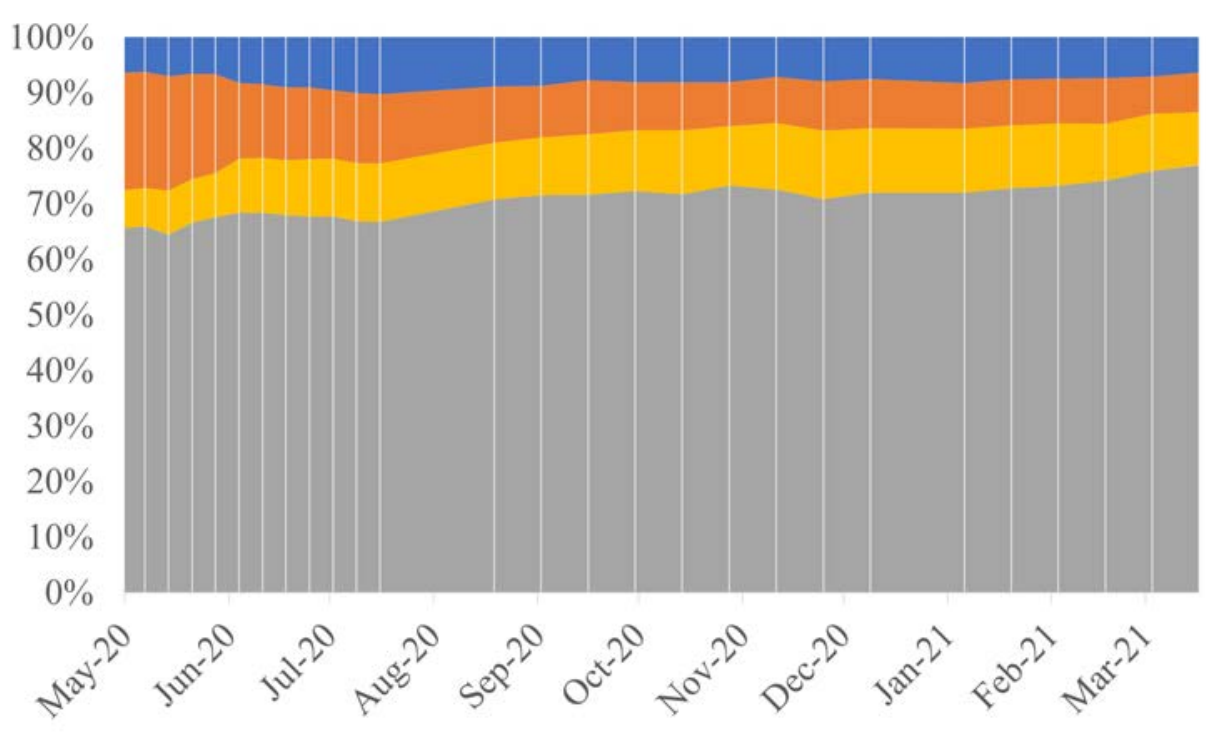

(b) 62-70 Year Olds

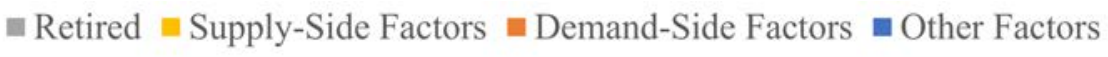

Notes: Responses to Census Pulse Survey question, "What is your main reason for not working for pay or profit?" Supply-side factors include not wanting to be employed, self/family member sick with coronavirus, caring for children/elderly, other sickness/disabled, concerned about spreading/getting coronavirus. Demand-side factors include layoffs/furloughs, employer temporary/permanent closure. 
Figure D.2: Effect of Pandemic on Social Security and Medicare Application Plans

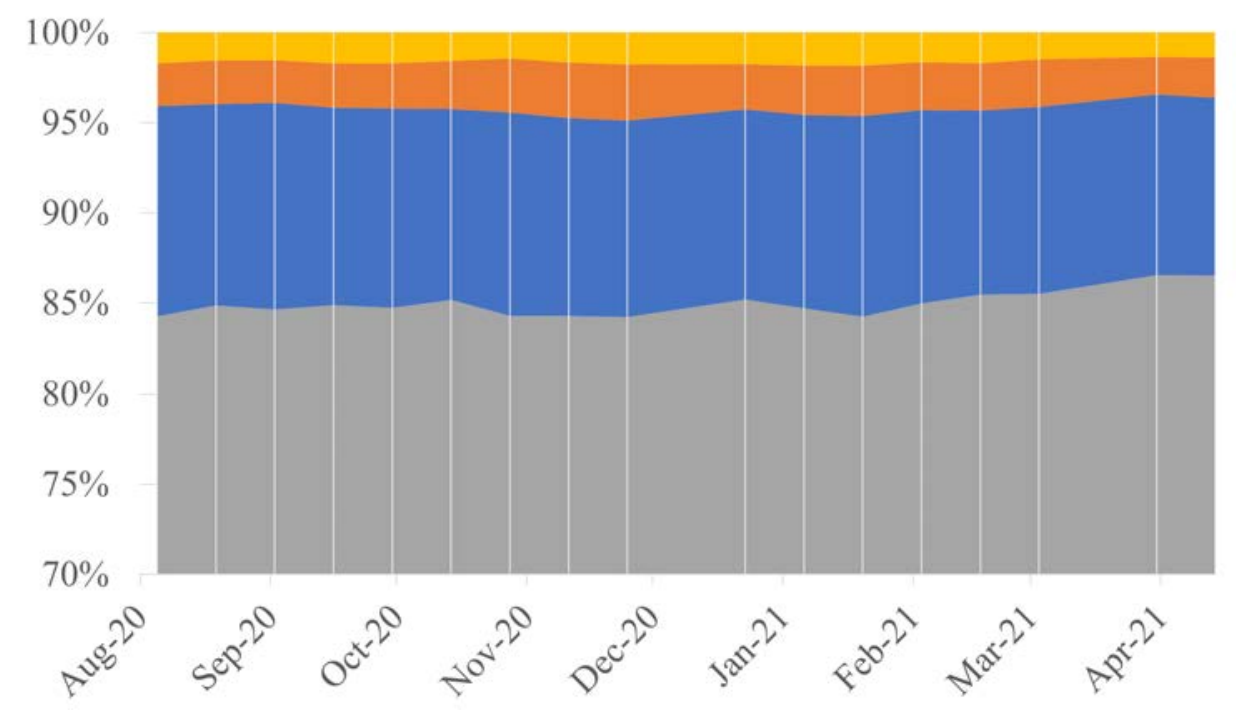

(a) 50-61 Year Olds

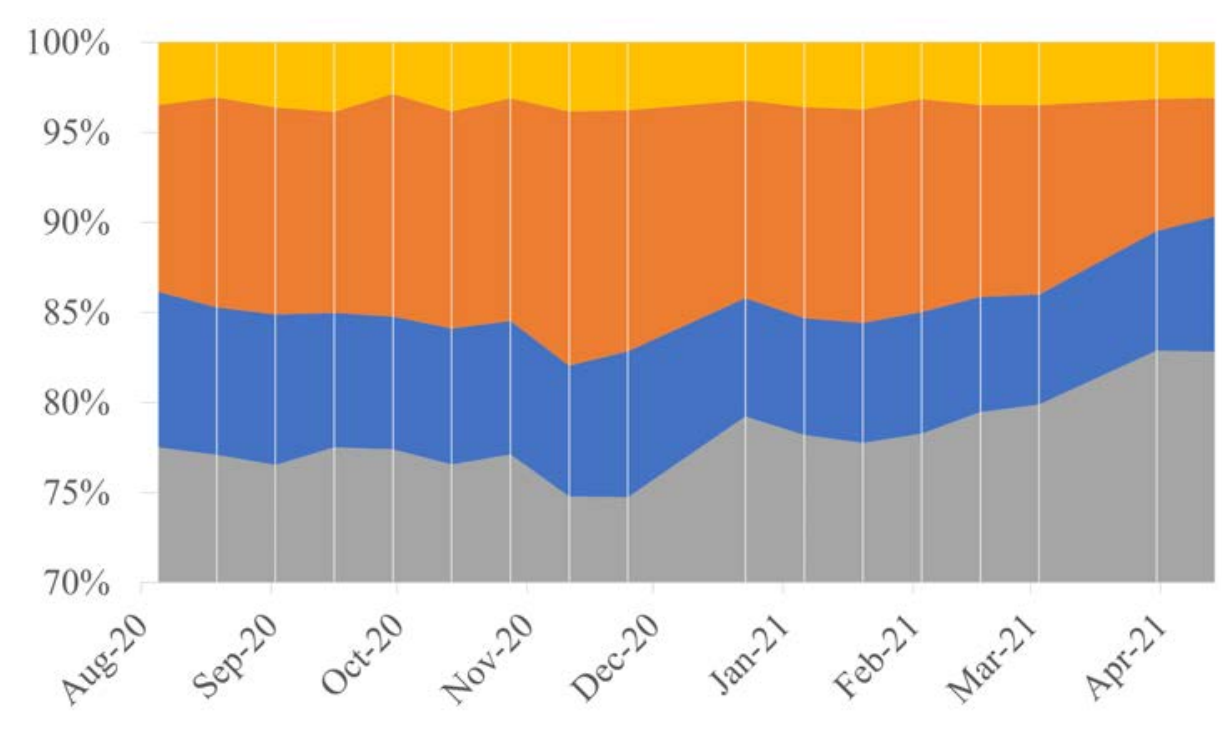

(b) 62-70 Year Olds

m No Effect $\square$ Decided Not to Apply $=$ Applied Earlier $=$ Applied Later

Notes: Responses to Census Pulse Survey question, "How has the coronavirus pandemic affected your decision about applying or not applying for Social Security benefits (Retirement, Disability, or Survivors), Supplemental Security Income (SSI) benefits, or Medicare benefits?" 
Figure D.3: Decision Not to Apply for Social Security by UI Application

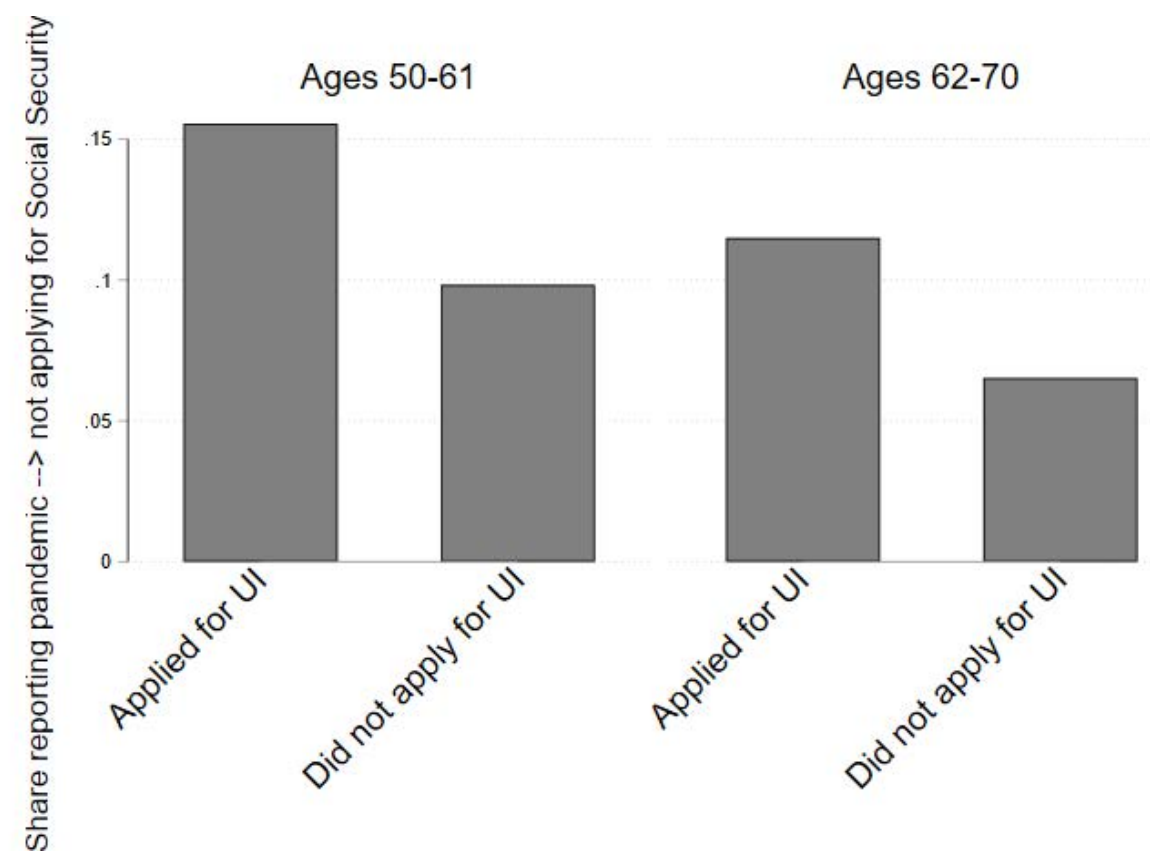

Notes: Share responding that pandemic caused not to apply for Social Security benefits (Retirement, Disability, or Survivors), Supplemental Security Income (SSI) benefits, or Medicare benefits by UI application, August 2020-April 2021. 


\section{Appendix E: CPS Measures of Disability}

Table E.1: Changes in Self Reported Disability Following COVID-19 Pandemic

\section{A. 50-61-Year-Olds}

\begin{tabular}{lccccccc}
\hline \hline & $(1)$ & $(2)$ & $(3)$ & $(4)$ & $(5)$ & $(6)$ & $(7)$ \\
& Any & Hearing & Vision & Memory & ADL1 & ADL2 & IADL \\
\hline Post Covid & -0.00368 & 0.000262 & $-0.00144^{* *}$ & $-0.00286^{* *}$ & -0.00331 & -0.00119 & -0.00103 \\
& $(0.00263)$ & $(0.00102)$ & $(0.000698)$ & $(0.00139)$ & $(0.00214)$ & $(0.00114)$ & $(0.000982)$ \\
\hline Observations & 1505301 & 1505301 & 1505301 & 1505301 & 1505301 & 1505301 & 1505301 \\
Pre-Covid Mean & 0.125 & 0.0247 & 0.0181 & 0.0396 & 0.0811 & 0.0405 & 0.0224 \\
\hline \hline
\end{tabular}

B. 62-70-Year-Olds

\begin{tabular}{lccccccc}
\hline \hline & $(1)$ & $(2)$ & $(3)$ & $(4)$ & $(5)$ & $(6)$ & $(7)$ \\
& Any & Hearing & Vision & Memory & ADL1 & ADL2 & IADL \\
\hline Post Covid & $-0.00501^{*}$ & -0.000617 & -0.00160 & $-0.00187^{*}$ & $-0.00730^{* * *}$ & -0.000355 & -0.000936 \\
& $(0.00253)$ & $(0.00182)$ & $(0.00146)$ & $(0.000950)$ & $(0.00260)$ & $(0.00113)$ & $(0.000673)$ \\
\hline Observations & 999143 & 999143 & 999143 & 999143 & 999143 & 999143 & 999143 \\
Pre-Covid Mean & 0.183 & 0.0528 & 0.0253 & 0.0396 & 0.121 & 0.0518 & 0.0288 \\
\hline \hline
\end{tabular}

Standard errors in parentheses

${ }^{*} p<0.10,{ }^{* *} p<0.05,{ }^{* * *} p<0.01$

Notes: Samples contain civilians ages 50-61 and 62-70 from the January 2015-March 2021 CPS living in the United States. Outcome variable is whether or not an individual reports having any disability. Disabilities are subdivided in to hearing, vision, memory, activities of daily living (ADL), and instrumental activities of daily living (IADL). ADL1 is defined as a difficulty walking or climbing stairs, ADL2 is defined as difficulty dressing or bathing, and IADL is defined as difficulty doing errands. Standard errors are robust and clustered at the state level. Standard errors are robust and clustered at the state level. Estimates are weighted using survey weights. The Post-Covid estimate captures the change in disability outcome using January 2015-February 2020 as the pre-period and March 2020-March 2021 as the post-period. Regressions include a time trend, and month and state fixed effects, and adjust for age, sex, race, Hispanic ethnicity, education, and household family size. Pre-Covid means captures the mean of the dependent variable in the pre-period January 2015-February 2020. 